\title{
Expected Returns on Real Investments: Evidence from the Film Industry
}

\section{Citation}

Powers, Thomas Y. 2014. Expected Returns on Real Investments: Evidence from the Film Industry. Working Paper, Harvard University.

\section{Permanent link}

http://nrs.harvard.edu/urn-3:HUL.InstRepos:17692595

\section{Terms of Use}

This article was downloaded from Harvard University's DASH repository, and is made available under the terms and conditions applicable to Other Posted Material, as set forth at http:// nrs.harvard.edu/urn-3:HUL.InstRepos:dash.current.terms-of-use\#LAA

\section{Share Your Story}

The Harvard community has made this article openly available.

Please share how this access benefits you. Submit a story.

\section{Accessibility}




\title{
Expected Returns on Real Investments: Evidence from the Film Industry
}

\author{
Thomas Y. Powers*
}

First Draft: February 1st, 2014
This Draft: June 27th, 2014

\begin{abstract}
Asset pricers generally study the pricing of secondary market securities. Using a proprietary, project-level dataset on the film industry, I am able to study a cross-section of expected returns on real investments instead. One area in which we might expect differences is in the pricing of idiosyncratic risk. I find that expected returns are both increasing and concave in the idiosyncratic dollar variance of a film's payoff. Plotting expected returns against dollar volatility yields an approximately linear relationship, in which a \$1 MM increase in volatility raises expected return by at least 43 basis points, up to as much as 116 basis points depending on the specification. I discuss several theories from corporate finance that can rationalize the pricing of idiosyncratic risk, and I build a matching model between studios and films in which costly external finance can explain both facts.
\end{abstract}

JEL Codes: G12, G32, L22.

Keywords: Cross-sectional asset pricing, pricing real investments, project choice, managerial risk aversion, risk management

\footnotetext{
*Harvard University, tpowers@hbs. edu. I am very grateful to John Campbell, Robin Greenwood, Victoria Ivashina, Diane Kahng, Steve Kovacs, Ari Levinson, Jean-Marie Meier, Filippo Mezzanotti, Vijay Narasiman, Jonathan Rhinesmith, David Scharfstein, Neil Shephard, Manpreet Singh, Erik Stafford, Luis Viceira, John Zhou, Eric Zwick, and the participants at the Harvard Finance Workshop and at the LBS Trans-Atlantic Doctoral Conference for their helpful comments. Additionally, I would like to thank Bruce Nash and OpusData for generously providing data and for feedback on my project.
} 


\section{Introduction}

Businesses expect different returns on different projects, and these differences determine which innovations are developed, which jobs are created, and which investments are available to savers. Nevertheless, despite its relevance, we know relatively little about which factors drive the cross-sectional variation in expected returns for real projects.

In studying this question, our key challenge is that we cannot observe costs. When a firm undertakes a project, it does not have to notify anyone. The cost of financing the project is often unreported, or may be reported only as part of a firmwide aggregate. Investments are not even necessarily priced by outsiders: a price may simply be the shadow price of internal funds faced by corporate decisionmakers, which is inherently unobservable.

In this paper, I use a proprietary, project-level dataset on the film industry to study one cross-section of expected returns on real investments. Using this dataset allows me to overcome several issues. First, we have comprehensive data on costs and revenues for a large cross-section of projects. Second, large studio movies are almost never produced then not released; so selection bias is minimal. Third, movie returns have very low correlations with the market, so we do not need to control for market risk premia when explaining their returns. Finally, movies differ cross-sectionally in observable ways; in particular, certain characteristics might make movies more or less risky, and thus price the cross-section.

One area in which the pricing of real projects might differ from, say, stocks, is in the pricing of idiosyncratic risk. In liquid secondary markets, we usually think of certain risks as frictionlessly diversifiable, and thus unable to earn any compensation. But in primary markets, frictions may create a spread in expected returns between projects with high and low idiosyncratic risk. For example, a high idiosyncratic risk project might lead to a higher probability of bankruptcy, and if bankruptcy has deadweight costs, firms should demand higher expected returns to produce such a project.

\section{Empirical Findings}

The simplest way to measure the risk of a movie is by estimating the dollar variance of its payoff. "Dollar variance" means the variance of the dollar return. Under this metric, the risk of a portfolio of movies is just the sum of the risks of its components (assuming statistical independence). This property captures the intuition 

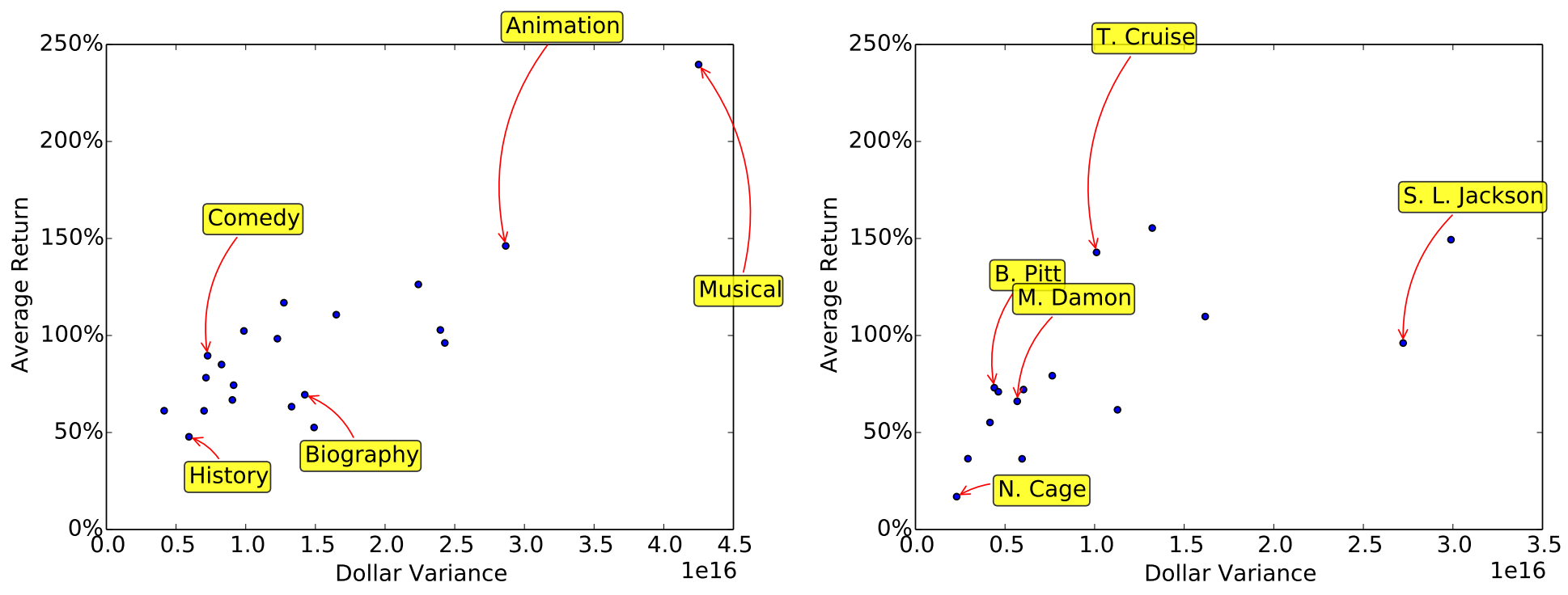

Figure 1: Returns are increasing and concave in dollar variance. Movies clustered by left: genres; right: actors.

that the risk contribution of each movie should be film-specific, rather than a function of the other movies produced by the same studio.

Figure 1 plots expected returns on films against these dollar variances. Each point represents a movie characteristic; for example, in the left panel, I group movies by genre, and then plot the average return and sample dollar variance within each genre as a point. The right panel applies the same process for actors with more than thirty films, a bound I impose to ensure that small sample effects do not drive the results.

Figure 1 shows that expected returns are increasing and concave in dollar variance. One way to quantify this statement is to assume parametrically a linear relationship between expected return and dollar volatility (the standard deviation of dollar returns), and then estimate that relationship using GMM. This linear relationship is plotted in figures 10,13, and 16. In my estimation, both the "right-hand variable" and the slope are estimated, since the risk of each movie must be fitted from its associated characteristics. When I run this procedure, I find that a $\$ 1 \mathrm{mil}-$ lion increase in the dollar volatility of payoffs raises expected returns for a film by at least 43 basis points, with the effect being as large as 116 basis points depending on the specification.

When computing these estimates, I take the heavy-tailed nature of the data seriously. Heavy tails can lead to spuriously small rejection regions. Additionally, 
heavy tails combined with skewness can lead to a small-sample bias. The bias arises if characteristics, say, film genres, have too few movies associated with them. Then, those characteristics that are lucky enough to be associated with positive tail outcomes will exhibit both high risk and return. Consequently, we will observe a spurious correlation between the two variables. I use a bootstrap procedure to correct the initial GMM estimates for bias and compute the appropriate confidence regions. I also compute risk using interquartile ranges, which may be less sensitive to heavy tails, and still observe a positive relationship between risk and return.

A key assumption behind my estimates is that all movie risk is idiosyncratic, so I do not need to control for market (or other) risk premia. To support this idea, I review previous literature showing that as much as $80 \%$ of the variation in box office revenues can be explained by film-specific characteristics, such as critics' ratings, the inclusion of a star actor, the initial budget, or the MPAA rating (G, PG, etc.). Moreover, I study aggregate data and find that the industry's domestic profits are not correlated with the U.S. business cycle. These findings are consistent with previous studies, which I also review. Finally, I argue that even if movies had different amounts of systematic risk, they would have to have implausibly large differences in betas in order to generate the spreads in expected returns I find.

\section{Theory}

Much of the literature assumes project risk can be perfectly passed through to public markets, so they are priced by that market's stochastic discount factor. This assumption is mostly a convenient simplification, however; Holmstrom (1989) argues that in reality, "firms do care about idiosyncratic risk" when deciding the "amount of money to be allocated among proposed projects," even if secondary markets do not.

In fact, corporate finance theory provides us with several possible frictions explaining why firms might price idiosyncratic risk in real investments:

- Bankruptcy might cause deadweight losses; for example, legal fees, or the early liquidation of otherwise good projects. Risk that could lead to bankruptcy therefore carries a cost.

- Financiers might pay a premium for low-risk secondary market securities, since firms that issue them don't need to be monitored as heavily. Thus, firms should be able to raise capital at more attractive rates if they take less risk. 
- Managers don't care about shareholders, but rather about their own careers. Taking on risky projects threatens their jobs. Consequently, even if shareholders could perfectly diversify project risk across firms, managers avoid it.

To gain insight, I develop a reduced-form model of the industry incorporating some of the above features. Although my dataset is not rich enough to differentiate sharply between the possible mechanisms, the model is relatively simple and explains the facts.

In the model, firms with more equity in the form of internal cash face smaller frictions. I make the reduced-form assumption that financiers allow these firms to borrow more dollars, and charge them less for taking on risky investments. I model these risk charges as deadweight losses from the frictions, so they are not a risk premium collected by financiers. On the supply side, projects are created by screenwriters and are matched to studios endogenously. Expected returns vary across projects because firms pay different prices for the projects they acquire.

Projects are indivisible, which captures the intuition that there are limits to diversification at the studio level. This assumption poses a technical challenge: in Arrow-Debreu equilibrium, prices can be found using marginal arguments; but it makes no sense to talk about a "marginal amount" of an all-or-nothing investment. Thus, I remove the Walrasian auctioneer and assume that matching takes place in a more general setting, a combinatorial Vickrey-Clarke-Groves auction. The resulting equilibrium maintains similarities to Arrow-Debreu equilibrium (existence, efficiency, incentive compatibility, etc.), while providing a mechanism for pricing indivisible goods.

I prove two key results about prices that are borne out in the data. First, idiosyncratic risk is priced: if the dollar variance of a project's return is increased (infinitesimally), its equilibrium expected return increases. Second, expected returns are "concave" in the sense that, if two projects have sufficiently different levels of dollar variance, and the riskier project is assigned to a larger firm, the riskier project's expected return will be less affected by additional risk. The intuition is that the riskier project will be priced by a firm that is larger and, ipso facto, less averse to risk.

The rest of the paper is structured as follows. I first review the literature on this topic. Next, I write down my model to explain my findings. I then introduce my dataset. Finally, I describe my empirical methodology and the findings themselves. 


\section{Related Literature}

\section{Real investment opportunities}

To my knowledge, this is the first paper that uses a large panel of project-level data to test a cross-sectional theory of expected returns. Nevertheless, there have been a number of papers, both theoretical and empirical, that model the real investment opportunities available to firms.

Belo (2010) has some similarities to this paper, and is a good representative for the growing literature on production-based asset pricing. In Belo's model, firms have a technology that allows them to invest in different "projects" (I use quotes because these projects are not discrete). Firms invest until, on the margin, the expected return from further investment, less the marginal adjustment cost, equals the marginal cost of capital, which is set according to a stochastic discount factor in the market for firm-issued liabilities. The fact that the secondary market stochastic discount factor "passes through" to projects undertaken by the firm implies that there are no substantive differences, aside from adjustment costs, in pricing between real projects and secondary market investments.

Greenwood and Hanson (2013) study the time series of returns to owning a dry bulk cargo ship. They find that behavioral factors (extrapolative expected returns) are necessary to explain the joint time variation in investment and returns. This study is similar to the present work in two ways: first, in the use of project-level data, and second, in the development of a theory for the formation of expected returns on the part of managers. I focus more on cross-sectional differences in expected returns between projects, however, rather than how expected returns deviate from rational expectations over time.

\section{The pricing of idiosyncratic risk}

The idea that idiosyncratic risk should not be priced goes back to the original theory of the CAPM (Treynor 1961, Sharpe 1964, Lintner 1965, Mossin 1966). In these two-period models, any risk that can be completely diversified away should not command an expected return, since investors can frictionlessly divide and share these risks.

Merton (1987) qualified these results by imagining a world in which diversification was necessarily incomplete, because investors either do not know about the whole universe of risks, or cannot access them through standard channels like the 
stock market. In Merton's world, if a risk has to be less widely held (more concentrated) due to these frictions, its equilibrium expected return should rise, since the holders of that risk have no way to share it.

Ang, Hodrick, Xing, and Zhang (2006) tested these theories. They found that stocks with higher levels of idiosyncratic risk tended to perform worse, not better. This poor performance could not be explained by "exposures to size, bookto-market, leverage, liquidity, volume, turnover, bid-ask spreads, coskewness, or dispersion in analysts' forecasts". Fu (2009) provided one explanation of these findings. He argued that Ang, Hodrick, Xing, and Zhang's result is driven by stale (1-month lagged) estimates of volatility; according to $\mathrm{Fu}$, idiosyncratic risk changes very quickly, making lagged estimates of volatility inappropriate. When $\mathrm{Fu}$ addresses this issue by using an EGARCH model for conditional volatility, he finds a positive contemporaneous relationship between expected returns and idiosyncratic risk.

\section{Corporate finance theories of risk management}

The corporate finance literature has developed several models explain why firms "manage risk" (avoid risk that is not priced by external markets). In general, when firms face costs of external finance, they will manage their risk. The reason is that firms want to preserve their internal cash so as to avoid these costs. This point is made Froot, Scharfstein, and Stein (1993). My paper builds on that literature by thinking of investing in low-risk projects as a form of risk managment.

It is also possible that external financing becomes more costly when firms take on riskier projects. This would generate an effect on top of the one just mentioned. For example, bankruptcy might have deadweight costs, so risk that increases the probability of bankruptcy would be avoided by the firm (Smith and Stulz 1985). There may also be higher monitoring costs associated with liabilities issued by riskier firms; a firm that issues perfectly riskless liabilities need not be monitored at all.

Alternately, career concerns could explain managerial risk aversion (Hirshleifer and Thakor 1992). If a $\$ 100$ million movie bombs at the box office, it will hurt the careers of the associated producers. This "limits to diversification" story is particularly plausible because producers need to be exposed to exactly this sort of idiosyncratic risk to have the proper incentives for success. 


\section{A matching model of the film industry}

In this model, projects and firms exist exogenously, with firms subject to financial constraints (implemented in a reduced form). The projects match to firms endogenously, leading to price formation. The variation in the prices leads to variation in expected returns.

In particular, because of the financial constraints, firms are more averse to risk than the secondary market is. Thus, when they buy projects, the price they are willing to pay depends on the project's risk, and riskier projects must pay higher expected returns in equilibrium. Moreover, since riskier projects are held by firms that are better cost avoiders for risk, marginal risk added to a very risky project has a less of an effect on expected return than it would for a low-risk project. This claim is similar to the concavity in expected returns we observe in the data.

After explaining the model, I prove the above points, adding for good measure a Modigliani-Miller-like result showing that expected returns should be constant across all projects if we remove financial constraints.

\section{Supply Side}

There are $N$ screenplays ready for production, numbered 1 to $N$, comprising the set $S$. Each screenplay has two characteristics. First, it has an investment size $I_{i}$ (measured in dollars). Second, the payoff of the project is the random variable $I_{i}\left(1+\widetilde{Q}_{i}\right)$, and every project has a cumulative distribution function $\mathcal{F}_{i}$ for the gross return $1+\widetilde{Q}_{i} . \mathcal{F}_{i}$ has bounded first and second moments. The project returns are statistically independent and independent of the market return.

Each screenplay will either match to a production studio or expire worthless. If produced, a screenplay will be purchased by a studio for a price $p_{i}$, on top of the investment cost $I_{i}$. Thus, the return to the studio will be

$$
1+\widetilde{R}_{i}=1+\widetilde{Q}_{i}-\frac{p_{i}}{I_{i}}
$$

For simplicity, we assume that variation in expected studio returns comes from variation in the acquisition prices of the projects, which are driven by screenplay characteristics. Thus, we set $\mathrm{E}\left(\widetilde{Q}_{i}\right)$ to be identical across screenplays and greater than the risk-free rate $R_{f}$. Intuitively, this restriction implies movies are heterogenous only in size and "risk" (non-first-moments), and we focus solely on how these two factors affect expected returns. 


\section{Demand Side}

There are $J$ firms, numbered 1 to $J$. Every firm $j$ has a level of internal cash $w^{j}$. I adopt a reduced-form specification for financial frictions. First, each firm $j$ has a borrowing limit $e^{j} \geq 0$, which is a function of $w^{j}$. We can think of this limit as some kind of leverage constraint that prevents the equityholders from having an incentive to take too much risk at the expense of the debtholders. Second, firms face a deadweight cost of risk (variance) $\gamma^{j}>0$. This can be thought of as a present value of deadweight bankruptcy costs that might be incurred in the future. Both parameters, $e^{j}$ and $\gamma^{j}$, are increasing in internal cash $w^{j}$.

We think of each firm having a utility function defined over the bundle $b$ of projects it ends up developing. A bundle is simply a subset of $S$, the set of all projects. The utility function is quadratic:

$$
U^{j}(b)=\underbrace{\mathrm{E}\left[\sum_{i \in b} I_{i}\left(\widetilde{Q}_{i}-R_{f}\right)\right]-\gamma^{j} \operatorname{Var}\left[\sum_{i \in b} I_{i} \widetilde{Q}_{i}\right]}_{V^{j}(b)}-P_{b_{k}}
$$

where $V^{j}(b)$ is the value the firm $j$ assigns to bundle $b$, and $P_{b}$ is the acquisition price for bundle $b$.

The riskless rate term $R_{f}$ in the expectation represents the fact that the firm has the outside option of investing its cash in a riskless account, and it is also allowed to borrow at the same rate, since the projects the firm produces are uncorrelated with the market. However, creditors do impose a (not necessarily binding) aggregate limit on the size of the firm, which is equivalent to a borrowing constraint given a fixed level of internal cash:

$$
\sum_{i \in b} I_{i} \leq e^{j}
$$

which must be satisfied for any bundle $b_{k}$ for which a firm wishes to place a positive bid. The idea is that a firm will not be willing to bid anything for a bundle of projects that it cannot afford to produce.

\section{Matching}

Screenplays are sold to firms in a combinatorial Vickrey-Clarke-Groves auction. This setup allows us to price "lumpy" projects rather than the infinitely divisi- 
ble assets of the Arrow-Debreu model. Moreover, firms can bid on sets of projects rather than individual projects. This feature is necessary to capture (anti-)complementarities: for example, a firm may bid $\$ 1$ for project $A, \$ 1$ for project $B$, but $\$ 0$ for both $A$ and $B$ because it cannot afford to produce both.

The VCG auction retains many of the useful properties of Arrow-Debreu equilibrium: first, we have a notion of asset prices, which is not necessarily the case in matching algorithms. An "equilibrium" always exists, prices are unique, and the allocation maximizes the welfare of the participants (although not necessarily the auctioneer). Furthermore, under this mechanism, it always a dominant strategy for a firm to bid its true valuations, so we need not assume an omniscient central planner.

Economically, a VCG auction differs from other matching algorithms in that it makes particular implicit assumptions about the bargaining power of screenwriters. Namely, screenwriters do not collude to revenue-maximize. Instead, their bargaining power is limited to their ability to match with a different firm. For example, if only one studio were interested in a particular bundle of screenplays, that studio would be able to bargain the price of that bundle down to zero.

The auction works as follows:

1. Studios place bids for each bundle $b_{k}$, where $k$ is an index of a bundle, equal to their valuations $V^{j}\left(b_{k}\right)$. Given the rest of the mechanism, it is well-known that bidding truthfully is a dominant strategy.

2. The projects are allocated to the studios by a function $M(j)$ : the index of the bundle to be developed by firm $j$. This function is defined so that the match maximizes total welfare subject to the constraint that the same project cannot be developed twice. Welfare is defined as

$$
V=\sum_{j=1}^{J} V^{j}\left(b_{M(j)}\right)
$$

3. Bundle prices are determined as follows. First, let $V_{-j}^{*}\left(x^{*}\right)$ mean the welfare of all agents except $j$ at the welfare-maximizing allocation $x^{*}$ that we solved in step 2:

$$
V_{-j}^{*}\left(x^{*}\right)=\sum_{j^{\prime} \neq j} V^{j^{\prime}}\left(b_{M\left(j^{\prime}\right)}\right)
$$


Second, let $V_{-j}^{*}\left(x_{-j}^{*}\right)$ mean the welfare of all agents except $j$ at the allocation $x_{-j}^{*}$ that would maximize their welfare:

$$
V_{-j}^{*}\left(x_{-j}^{*}\right)=\sum_{j^{\prime} \neq j} V^{j^{\prime}}\left(b_{M^{\prime}\left(j^{\prime}\right)}\right)
$$

where $M^{\prime}\left(j^{\prime}\right)$ maximizes $\sum_{j^{\prime} \neq j} V^{j^{\prime}}\left(b_{M^{\prime}\left(j^{\prime}\right)}\right)$ subject to the constraint that the same project cannot be developed twice.

The price of the bundle assigned to $j$ is the second value minus the first: it is what the other players have to give up in order to assign the bundle $M(j)$ to $j$ instead of keeping it among themselves.

$$
P_{b_{M(j)}}=V_{-j}^{*}\left(x_{-j}^{*}\right)-V_{-j}^{*}\left(x^{*}\right)
$$

4. The price $p_{i}$ imputed to screenplay $i$ is its pro-rata share of the price of the bundle to which the project belongs. For example, if project $i$ is part of bundle $b_{k}$,

$$
p_{i}=\frac{I_{i}}{\sum_{j \in b_{k}} I_{j}} P_{b_{k}}
$$

\section{Characterizing matches}

A match is an allocation of bundles and prices resulting from the above auction. This section characterizes these matches.

Theorem 1. A match always exists, and prices are unique.

Proof. Because the welfare function is bounded, it has a (finite) supremum. Because the set of allocations is finite, the supremum is attained. Thus, at least one welfare-maximizing allocation can always be constructed. Prices are computed by taking differences of these welfare-maximizing allocations for different sets of agents.

Any welfare-maximizing allocation is not necessarily unique; for example, all firms could be identical, in which case the assignment of bundles to firms would be arbitrary. However, the maximized value of the welfare function is by definition unique, since if it were not, one of the multiple values would not be a maximum. 
Thus, the price expression is unique as it is the difference between two uniquely defined terms.

Definition. A match is locally stable with respect to a level of risk $s_{i}^{2}$ if there exists a $\varepsilon$ neighborhood $B$ around $\sigma_{i}^{2}$ such that, if $\sigma_{i}^{2}$ where changed to any other $\sigma_{i}^{2^{\prime}} \in B$, the matching function $M(j)$ would remain constant. (The purpose of this definition is to prevent the matching from changing discontinuously when we take derivatives around a level of $s_{i}^{2}$.)

Theorem 2. [Idiosyncratic risk premium.] Let the risk of project $i$ be defined as its dollar variance: $s_{i}^{2}=I_{i}^{2} \sigma_{i}^{2}$. A small, exogenous increase in risk for a screenplay raises its expected return:

$$
\frac{\partial \mathrm{E}\left(\widetilde{R}_{i}\right)}{\partial s_{i}^{2}} \geq 0
$$

where the derivative is taken holding $I_{i}$ constant, and evaluated for any level of risk $s_{i}^{2}$, for any project $i$, such that the matching is locally stable with respect to that level of risk.

Proof. Suppose that project $i$ is part of bundle $b_{k}$. Then, by substituting the expression for $p_{i}$ into the definition of expected return and taking expectations, we get:

$$
E\left(\widetilde{R}_{i}\right)=E(\widetilde{Q})-\frac{P_{b_{k}}}{\sum_{j \in b_{k}} I_{j}}
$$

where $\mathrm{E}(\widetilde{Q})$ is the common value of all $\mathrm{E}\left(\widetilde{Q}_{i}\right)$. Thus, the comparative static of interest has the same sign as

$$
-\frac{\partial P_{b_{k}}}{\partial s_{i}^{2}}
$$

To use this fact, note that the formula for $P_{b_{k}}$ is

$$
P_{b_{k}}=V_{-j}^{*}\left(x_{-j}^{*}\right)-V_{-j}^{*}\left(x^{*}\right)
$$

where $j$ is the index of the firm producing bundle $b_{k}$. This formula can be expanded 


$$
\begin{aligned}
P_{b_{k}}= & \sum_{j^{\prime} \neq j}\left[\sum_{i^{\prime} \in b_{M\left(j^{\prime}\right)}} \mathrm{E}\left(\widetilde{Q}_{i^{\prime}}-R_{f}\right) I_{i}-\gamma^{j^{\prime}} \operatorname{Var}\left(\sum_{i^{\prime} \in b_{M\left(j^{\prime}\right)}} I_{i^{\prime}} \widetilde{Q}_{i^{\prime}}\right)\right] \\
& -\sum_{j^{\prime} \neq j}\left[\sum_{i^{\prime} \in b_{M^{\prime}\left(j^{\prime}\right)}} \mathrm{E}\left(\widetilde{Q}_{i^{\prime}}-R_{f}\right) I_{i}-\gamma^{j^{\prime}} \operatorname{Var}\left(\sum_{i^{\prime} \in b_{M^{\prime}\left(j^{\prime}\right)}} I_{i^{\prime}} \widetilde{Q}_{i^{\prime}}\right)\right]
\end{aligned}
$$

where $M\left(j^{\prime}\right)$ is the true match and $M^{\prime}\left(j^{\prime}\right)$ is the match that would have been created if firm $j$ did not exist.

In this expanded expression, note that the risk of project $i$ only affects at most one term in the many summations. The reason is that, in the first set of summations, project $i$ does not appear at all because it is not assigned to any firm $j^{\prime} \neq j$. In the second set of summations, it appears at most once because project $i$ has been assigned to some other firm now (or to no firm), and thus contributes to either that firm's risk, or to no firm's risk. Using this fact, along with the independence of the project returns, we can write the partial derivative as

$$
\frac{\partial P_{b_{k}}}{\partial s_{i}^{2}}= \begin{cases}\gamma^{j^{\prime}} & \text { if assigned to a new firm } j^{\prime} \text { in the absence of } j \\ 0 & \text { if not assigned to any firm in the absence of } j\end{cases}
$$

Thus $-\partial P_{b_{k}} / \partial s_{i}^{2} \geq 0$, and $\partial \mathrm{E}\left(\widetilde{R}_{i}\right) / \partial s_{i}^{2} \geq 0$ as required.

Theorem 3. [Riskier projects are less affected by marginal risk.] For any project i produced by studio $j$ and a distinct, riskier project $i^{\prime}$ produced by studio $j^{\prime}$, if:

1. $i$ would be produced in the absence of $j$, and $i^{\prime}$ would be produced in the absence of $j^{\prime}$,

2. The risk gap $s_{i^{\prime}}^{2} / s_{i}^{2}$ is sufficiently large:

$$
\frac{s_{i^{\prime}}^{2}}{s_{i}^{2}}>\underbrace{\frac{I_{i} \mathrm{E}\left(\widetilde{Q}_{i}-R_{f}\right)}{\gamma^{N_{-j}(i)} s_{i}^{2}}}_{\text {benefit/cost for } i} \cdot \frac{I_{i^{\prime}}}{I_{i}}
$$

where $N_{-j}(i)$ is the index of the firm that produces $i$ in the absence of $j$,

3. The studio producing the riskier project has an equal or larger budget than the other 
studio:

$$
\sum_{w \in b_{M(j)}} I_{w} \leq \sum_{w \in b_{M\left(j^{\prime}\right)}} I_{w}
$$

Then, the riskier project's expected return will be less sensitive to risk:

$$
\frac{\partial \mathrm{E}\left(\widetilde{R}_{i}\right)}{\partial s_{i}^{2}} \geq \frac{\partial \mathrm{E}\left(\widetilde{R}_{i^{\prime}}\right)}{\partial s_{i^{\prime}}^{2}}
$$

where again the Is are treated as constants and the derivatives are evaluated at points $s_{i}^{2}$, $s_{i^{\prime}}^{2}$ at which the matching is locally stable.

Proof. Intuitively, riskier projects are produced by studios with lower risk aversion, so marginal risk is less costly. The key is to formalize that intuition: it is not exactly right because projects are priced based on the "second price" bidder rather than the actual firm that produces the project. Thus, we need the riskier project to be "sufficiently riskier" that we can strictly compare the second price bidders.

Now for the proof. Parametric condition 2 can be cross-multiplied and simplified to:

$$
\gamma^{N_{-j}(i)} s_{i^{\prime}}^{2}>I_{i^{\prime}} \mathrm{E}\left(\widetilde{Q}_{i}-R_{f}\right)
$$

Because $i^{\prime}$ is produced without $j^{\prime}$, the risk cost is less than the return benefit:

$$
\gamma^{N_{-j^{\prime}}\left(i^{\prime}\right)} s_{i^{\prime}}^{2} \leq I_{i^{\prime}} \mathrm{E}\left(\widetilde{Q}_{i^{\prime}}-R_{f}\right)
$$

Using the fact that $\mathrm{E}\left(\widetilde{Q}_{i}\right)=\mathrm{E}\left(\widetilde{Q}_{i^{\prime}}\right)$, we can combine the two inequalities to get the useful result:

$$
\gamma^{N_{-j}(i)}>\frac{I_{i^{\prime}} \mathrm{E}\left(\widetilde{Q}_{i^{\prime}}-R_{f}\right)}{s_{i^{\prime}}^{2}} \geq \gamma^{N_{-j^{\prime}}\left(i^{\prime}\right)}
$$

Now we directly compute expected returns. The expected return on film $i$ is

$$
\mathrm{E}\left(\widetilde{R}_{i}\right)=\mathrm{E}(\widetilde{Q})-\frac{P_{b_{M(j)}}}{\sum_{w \in b_{M(j)}} I_{w}}
$$


Take a derivative to get:

$$
\frac{\partial \mathrm{E}\left(\widetilde{R}_{i}\right)}{\partial s_{i}^{2}}=\frac{\gamma^{N_{-j}(i)}}{\sum_{w \in b_{M(j)}} I_{w}}
$$

where I have used the result from the previous proof: the slope of the bundle price with respect to the risk of a project is equal to the risk aversion of firm $N_{-j}(i)$, assuming $i$ is produced without $j$.

Similarly, the expected return on film $i^{\prime}$ satisfies

$$
\frac{\partial \mathrm{E}\left(\widetilde{R}_{i^{\prime}}\right)}{\partial s_{i^{\prime}}^{2}}=\frac{\gamma^{N_{-j^{\prime}}\left(i^{\prime}\right)}}{\sum_{w \in b_{M\left(j^{\prime}\right)}} I_{w}}
$$

Since $\gamma^{N_{-j^{\prime}}\left(i^{\prime}\right)}<\gamma^{N_{-j}(i)}$ and $\sum_{w \in b_{M\left(j^{\prime}\right)}} I_{w} \geq \sum_{w \in b_{M(j)}} I_{w}$ (by the third condition in the theorem statement), it follows that

$$
\frac{\partial \mathrm{E}\left(\widetilde{R}_{i}\right)}{\partial s_{i}^{2}} \geq \frac{\partial \mathrm{E}\left(\widetilde{R}_{i^{\prime}}\right)}{\partial s_{i^{\prime}}^{2}}
$$

as required.

Theorem 4. [Modigliani-Miller.] Expected returns are the same for all screenplays if there is at least one studio that is not borrowing constrained or risk-penalized.

Proof. The social welfare function is

$$
W=\sum_{j=1}^{J}\left[\sum_{i \in b_{M(j)}} \mathrm{E}\left(\widetilde{Q}_{i}-R_{f}\right) I_{i}-\gamma^{j} \operatorname{Var}\left(\sum_{i \in b_{M(j)}} I_{i} \widetilde{Q}_{i}\right)\right]
$$

This expression will be maximized by the VCG mechanism. The maximum occurs when all screenplays are assigned to a firm that is not borrowing constrained or risk-penalized. The reason is that we completely avoid any variance penalties, while not giving up anything on expected returns.

Because one firm is producing all projects, the price for each screenplay will be its pro-rated fraction of the bundle corresponding to the entire set of screenplays $S$ :

$$
p_{i}=\frac{I_{i}}{\sum_{j} I_{j}} P_{S}
$$


Regardless of the value of $P_{S}$, this implies that the expected return to the studio is

$$
\mathrm{E}\left(\widetilde{R}_{i}\right)=\mathrm{E}\left(\widetilde{Q}_{i}\right)-\frac{P_{S}}{\sum_{j} I_{j}}
$$

which is constant for all projects $i$.

\section{Data}

I use data from Nash Information Services' proprietary OpusData database. This dataset is primarily marketed to the film industry and contains detailed information on movie characteristics and financials. A public slice of the dataset can be viewed at http://www.the-numbers.com/, and the full dataset can be purchased at http://www. opusdata.com/.

The data are collected from industry sources. For example, domestic and international theatrical distributors report daily box office takes, which can be aggregated to get total box office grosses for each film. For some films, the database relies on publicly available numbers published in trade press, such as Variety, Screen International, Hollywood Reporter, etc. Additional information comes from domestic and international trade groups, such as the Digital Entertainment Group, European Audiovisual Observatory, National Association of Theater Owners, MPAA, BFI, etc. DVD tracking information come from Rentrak Home Media Essentials and Nielsen VideoScan.

Because OpusData has a relatively small number of genres, I also use genre classifications from the Internet Movie Database (IMDB), a property now fully owned by Amazon.com. Most people interact with this database through the website http://www.imdb.com/, which is the 45th most visited site in the world as of January 2014 (Alexa 2014). The full dataset is available as text files from http://www.imdb.com/interfaces; although some of these files require substantial processing before they can be inserted into a database. Matching films by title and release year, I can merge the genre classifications from IMDB with financials from OpusData.

As of April 2014, the OpusData dataset contains information on 19,973 movies. The earliest movie is from 1915, but the majority of films are recent: $83.3 \%$ of the films were released during or after 1990. The dataset also contains 3,988 directors, 45,258 actors, and 11,489 producers, all linked to their associated movies.

I prune the sample to address biases. First, I use only films with release year 
before 2013 to minimize under-reporting returns for films that are either still in theaters, or have yet to sell an appreciable number of DVDs. Second, to address selection bias within the remaining sample, I focus on the population of films that report spending over $\$ 10$ million 2012 dollars. Within this population, nearly all films are released (since the budget is a sunk cost), so there is no censorship problem. ${ }^{1}$ After removing these films, I am left with 2,853 films, $87.0 \%$ of which were released during or after 1990.

I compute the return on film $i$ using the following formula:

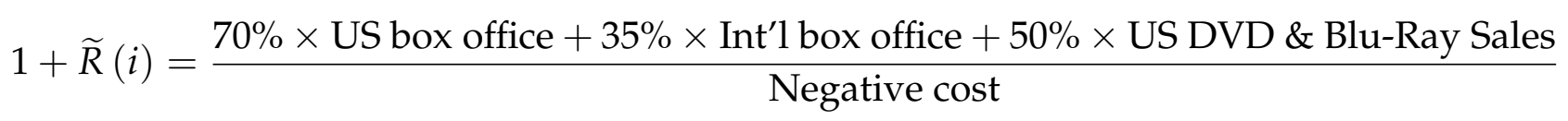

The percentages used in the numerator are typical values for the fraction of sales the studio itself is able to capture, based on Vogel (2011) and discussions with professionals in the industry. For example, domestic exhibitors (theaters) generally take about $30 \%$ of box office revenues, even though exhibition contracts are generally more complex than a simple percentage. Additionally, since distributing films outside the U.S. is often outsourced to foreign distributors, in that case the studio collects about half as much income per box office dollar as in the U.S.

The "negative cost" of a film is the cost of producing the "negative," or physical film. It does not include distribution or advertising costs. The reason for excluding these costs is that studios may inflate the latter figures to reduce taxes and payments to people owed a share of the profits. Forrest Gump is a classic example of this phenomenon; the screenwriter threatened legal action against the studio for declaring that the film was unprofitable after its hugely successful release (Weinraub 1995). The use of negative costs is standard in the literature; for example, see Ravid (1999).

One might reasonably ask whether the returns should be annualized in some way, to account for the fact that different movies take different amounts of time to complete. Specifically, movies that take longer to produce (in general, more expensive movies) might also be riskier; then, the higher measured returns on riskier movies would simply be due to a failure to annualize. Although it seems clear from Figures 6, 7, and 8 that size is not related to risk or return, it is worth addressing the annualization concern directly.

To annualize returns properly, I acquired production duration data from the

\footnotetext{
${ }^{1}$ On this point, see the relatively short list of "high profile films that remain unreleased" here: http://styleblazer.com/176218/hollywood-on-hold-14-high-profile-films-that-remain-unreleased/
} 


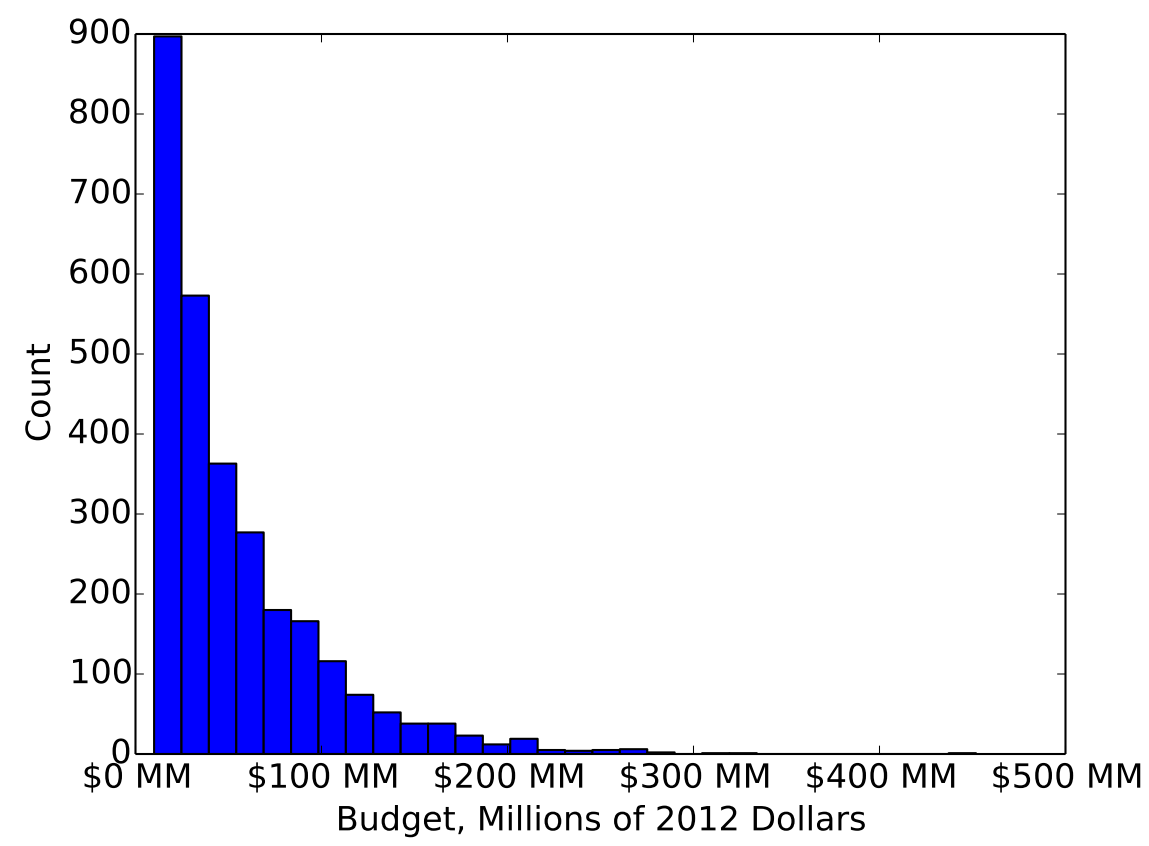

Figure 2: The distribution of budgets is skewed

Internet Movie Database. These numbers are available only for a 220-film subset, so the subset is too small to replicate my analysis when grouping movies by actors and directors (without introducing significant small-sample bias). Nevertheless, I find that the results with genre groupings are just as strong if we annualize properly; this is shown in Figure 12. My main results, however, do not include this annualization since I would like to use the full dataset.

The following plots illustrate key features of the dataset. First, note that the distribution of film budgets has an extremely long tail. Most movies above my $\$ 10$ million threshold cost less than $\$ 50$ million to make; yet there are some movies that cost more than $\$ 200$ million.

Second, the distribution of film returns has an extreme positive skew. As Ferrari and Rudd (2006) put it, "while the average ROI for all films in recent years has been positive, the majority of films yielded negative returns." Thus, film finance is very simliar to entrepreneurial finance; financiers generally lose money, but do so in order to capture rare, extreme gains.

Table 1 presents financial data on the biggest budget films in my dataset, and Table 2 presents summary statistics for the entire dataset. These are provided to show that data are reasonably accurate and also that there is a huge variation in returns. 


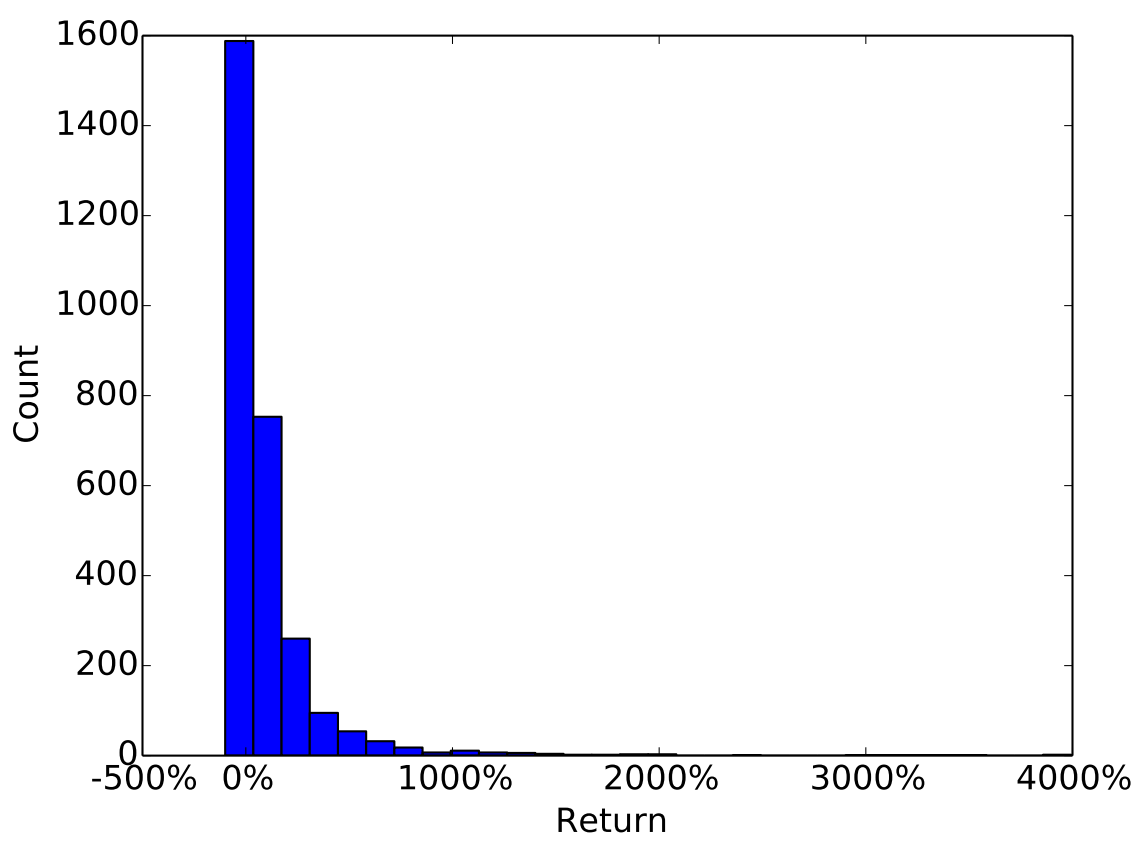

Figure 3: The distribution of returns is extremely skewed

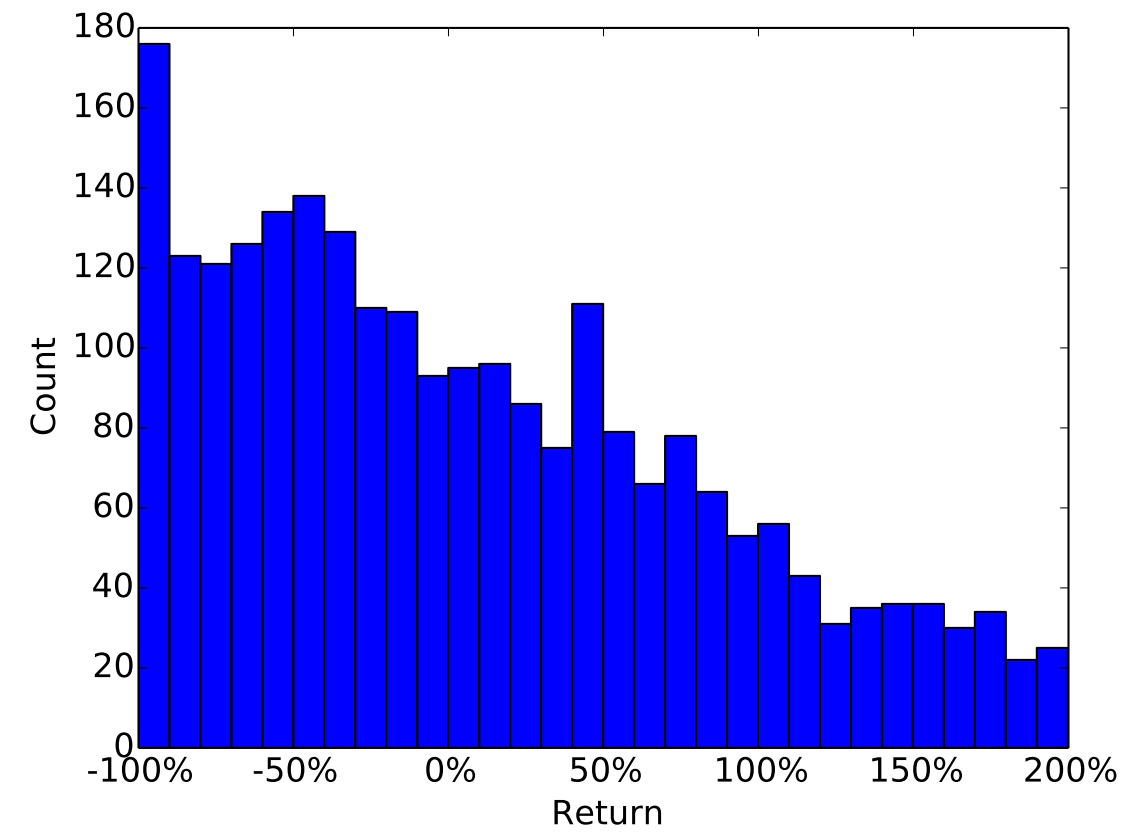

Figure 4: The distribution of returns, left end of the distribution 


\begin{tabular}{|lcrc|}
\multicolumn{1}{c}{ Budget (2012\$) } & Return & Year \\
\hline Avatar & $\$ 451 \mathrm{MM}$ & $233 \%$ & 2009 \\
Pirates of the Caribbean 3 & $\$ 328 \mathrm{MM}$ & $99 \%$ & 2007 \\
Cleopatra & $\$ 314 \mathrm{MM}$ & $8 \%$ & 1963 \\
Titanic & $\$ 286 \mathrm{MM}$ & $398 \%$ & 1997 \\
Spider-Man 3 & $\$ 282 \mathrm{MM}$ & $91 \%$ & 2007 \\
John Carter & $\$ 275 \mathrm{MM}$ & $-48 \%$ & 2012 \\
The Dark Knight Rises & $\$ 275 \mathrm{MM}$ & $122 \%$ & 2012 \\
Tangled & $\$ 273 \mathrm{MM}$ & $38 \%$ & 2010 \\
Harry Potter 6 & $\$ 266 \mathrm{MM}$ & $105 \%$ & 2009 \\
Superman Returns & $\$ 264 \mathrm{MM}$ & $7 \%$ & 2006 \\
\hline
\end{tabular}

Table 1: Highest budget movies

\section{Empirical Strategy}

My ultimate goal is to demonstrate an idiosyncratic risk premium in the crosssection of expected returns for films. The empirical strategy has five distinct steps:

1. Systematic risk is negligible. I review the evidence on the determinants of realized returns, and argue that nearly all of the variation in realized returns is explained by movie-specific factors. Individual movie returns do not correlate with the market, so we can treat them as idiosyncratic.

2. GMM restrictions for estimating risk. I use the dollar variance of each film as a proxy for idiosyncratic risk, as suggested by my matching model. Because we do not directly observe the ex-ante variance of returns for each film, I develop moment restrictions to estimate these parameters based on the characteristics of each film; namely, the genre, actors, and directors involved with the film.

3. GMM restrictions for estimating the risk premium. After estimating the risk of each movie, I develop a simple model in which there is a concave, squareroot relationship between dollar variance and expected returns. This parameterization describes the data well (based on plots) and leads to a linear moment condition relating dollar volatility and expected returns. 


\begin{tabular}{|lr|}
\hline Number of films & 2,853 \\
Median Budget & $\$ 38.0 \mathrm{MM}$ \\
Mean Budget & $\$ 53.6 \mathrm{MM}$ \\
Median \$ Return & $\$ 6.0 \mathrm{MM}$ \\
Mean \$ Return & $\$ 36.5 \mathrm{MM}$ \\
Median \% Return & $17.0 \%$ \\
Mean \% Return & $87.0 \%$ \\
Std. Dev. of \$ Returns & $\$ 111.7 \mathrm{MM}$ \\
Interquartile Range \$ Returns & $\$ 62.2 \mathrm{MM}$ \\
Std. Dev. of \% Returns & $281.8 \%$ \\
Interquartile Range \% Returns & $161.6 \%$ \\
\hline
\end{tabular}

Table 2: Summary statistics

4. Econometric issues. I discuss some of the econometric issues related to estimating GMM models with heavy-tailed data, and I propose a methodology based on bootstrapping to solve these issues.

5. I discuss an alternative risk measure for heavy-tailed data (the interquartile range), and show that it also predicts higher returns.

\section{Negligible systematic risk in films}

A key assumption in this paper is that films have market betas that are close to zero (more technically, betas to the stochastic discount factor). Thus, if I can find characteristics that create spreads in risk, and those spreads in risk correlate with returns, we are picking up an idiosyncratic risk premium rather than a systematic risk premium. But is the assumption of zero betas reasonable?

Regressions suggest that film returns are mostly driven by whether the individual film is good or not, rather than by macroeconomic conditions. Basuroy, Chatterjee, and Ravid (2003) report that $79 \%$ of the cross-sectional variation in firstweek box office revenue can be explained by reviews, whether the movie features a star, MPAA ratings (G, PG, etc.), and other non-business-cycle characteristics. Nor do macro factors kick in later: Moon, Bergey, and Iacobucci (2009) find that up to $90 \%$ of the variation in later-week box office revenue is explained by first-week revenue, in addition to standard movie-specific factors. 
On the aggregate level, the film industry is either acyclical or mildly countercyclical. Nardone (1982) documents a study conducted by A. Kapusinski who "matched 42 economic measures of the motion-picture industry... against similar variables used to assess the performance of the whole economy" and found that ticket sales were actually slightly countercyclical (cited in Vogel 2011). Summarizing the findings on the cyclicality of ticket sales, Vogel (2011) states that "ticket sales often remain steady or rise during early to middle stages of a recession, faltering only near the recession's end."

Figure 5 shows the acyclicality of film returns in my sample. In the top panel, I plot returns on the CRSP value-weight U.S. market portfolio alongside the median film return in my sample, excluding international box office grosses (so that U.S. data are being compared to U.S. data). The years along the $x$-axis correspond to the release years for movies. We can see that bad times for the market, such as 2000 and 2008, are not necessarily bad times at all for the film industry. The middle panel shows the same plot, just with the international data added back in for robustness. Finally, the bottom panel plots U.S. movie grosses, which includes box office take along with DVD and Blu-Ray sales. Thus number grows over time but does not seem to be correlated with either the equity market or output. Overall, these results are consistent with the findings just reviewed.

Finally, given the double-digit percentage point spreads in expected returns that I find, betas would have to be implausibly large for a systematic risk story to "work." For example, when grouping movies by both genre and director (see Figure 1), I find that some genres and directors differ by over 100 percentage points in expected return. Even if this return were earned over two years, given the size of the equity risk premium (perhaps 5\%), one would need different types of movies to have beta differences of at least ten to explain my results using systematic risk. It is hard to believe we have movies that go up in value by $10 \%$ whenever the market appreciates by $1 \%$, and it is just as hard to understand how two movies could differ by 10 units in beta. Even if the returns were earned over five years, we would need beta differences as large as four to explain the results.

Although one can find news articles suggesting that recessions tighten financing conditions for movies, this is different from saying that realized movie returns covary with realized market returns. At best, it says that the level of expected returns on films rises and falls with the expected return on the market. 

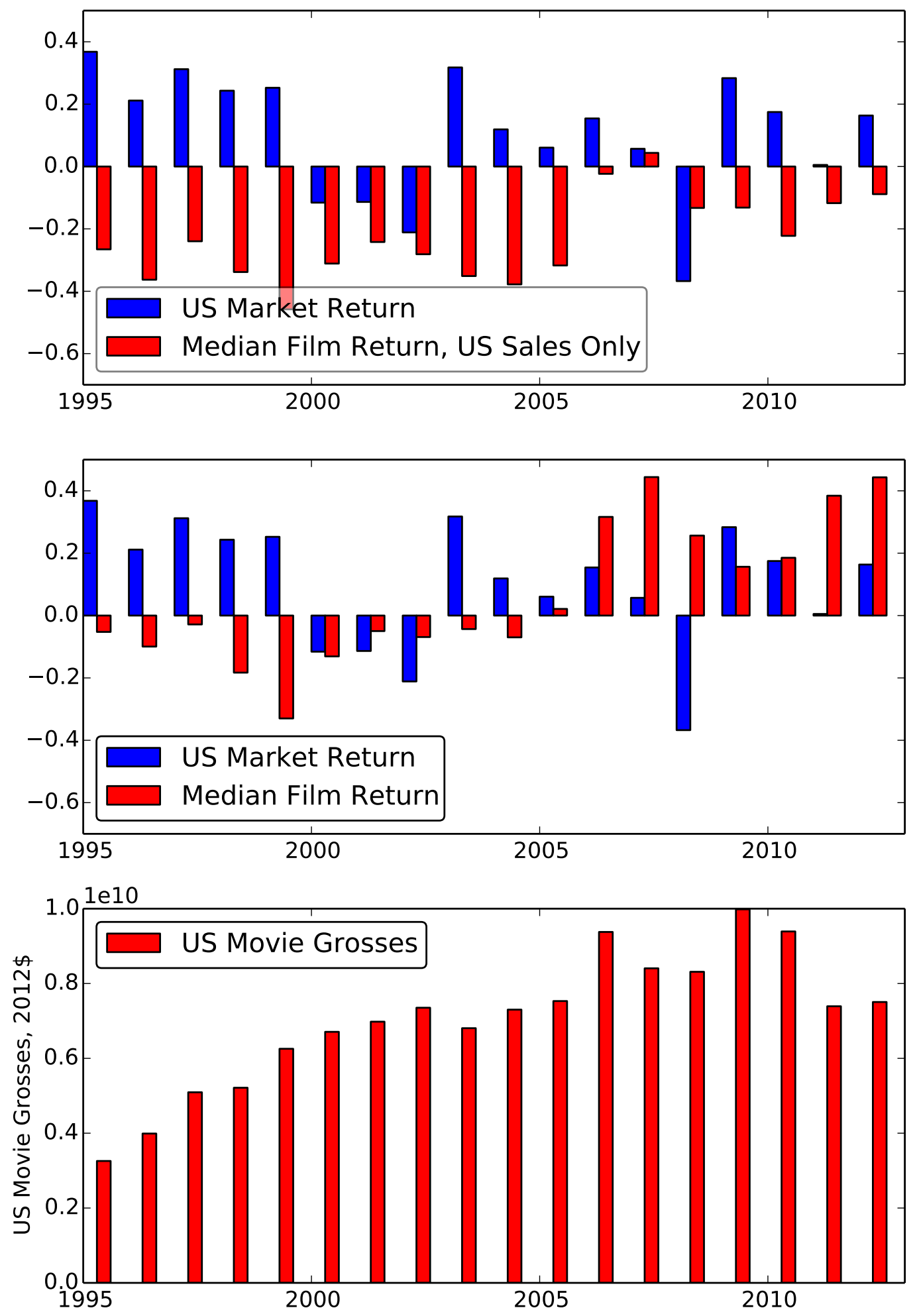

Figure 5: Studio profits are acyclical. Top: CRSP value-weighted U.S. market return and the median return on all films, excluding the international box office. Middle: same as Top, but including the international box office. Bottom: total U.S. film grosses, including DVD and Blu-Ray sales. 


\section{Modeling idiosyncratic risk}

I use the dollar variance of a movie as my measure of risk. This measure, which is simply the expected squared deviation of the dollar return from its mean, is convenient for the following reason. If firms are averse to "risk," by using dollar variance as our risk measure, we ensure that the quantity of risk a film adds to any studio's portfolio is exactly the same. The reason for this is that variances of independent dollar returns are additive, which other measures like standard deviation are not (standard deviation is subadditive). Consequently, if we had used one of these other measures, a key factor in determining a movie's risk would be the identity of the other films produced by the same studio, which would be tricky to deal with parametrically. Later, we will see that two other measures of risk, volatility and interquartile range, generate similar spreads in expected returns, so this choice is fairly innocuous.

We don't observe dollar variances, but we can estimate them based on characteristics of movies. For example, movies with certain actors or directors, or belonging to certain genres, tend to have different levels of risk. Interestingly, movies with different budget sizes do not necessarily have different levels of risk: the bigger-budget movies which one might imagine to be riskier also have less uncertainty about their percentage returns, which tends to work against the first effect.

To formalize this, let a "group" be a set of movies that share a characteristic; for example, "movies featuring Tom Cruise" would be a group. Let $1_{i g}$ be the indicator variable equal to one when movie $i$ is in group $g$. Then, let us suppose (parametrically) that the idiosyncratic dollar cash-flow variance on movie $i$ is the average of weights $w_{g}$ corresponding to the groups $g$ to which $i$ belongs:

$$
\sigma_{\$, i}^{2} \equiv \frac{\sum_{g \in G} w_{g} 1_{i g}}{\sum_{g \in G} 1_{i g}}
$$

For robustness, I also consider a geometric average specification for $\sigma_{\$, i}^{2}$ although the results are quite similar:

$$
\sigma_{\$, i}^{2} \equiv \exp \left(\frac{1}{\sum_{g \in G} 1_{i g}} \sum_{g \in G} \ln \left(w_{g}\right) 1_{i g}\right)
$$

In either case, the denominator term normalizes for the number of groups in which movie $i$ is a member.

Then, we can write down a moment restriction for each group $g$ that forces the 
values of this parameter $\sigma_{\$, i}^{2}$ to actually be close to the realized dollar variance in that group:

$$
\mathrm{E}\left(\left(\left(R_{i}-\mathrm{E}\left(R_{i}\right)\right)^{2} I_{i}^{2}-\sigma_{\$, i}^{2}\right) 1_{i g}\right)=0 \quad G \text { restrictions }
$$

where $I_{i}$ is the budget for movie $i$.

These $G$ conditions are sufficient to identify the $G$ parameters $\left\{w_{g}\right\}$. However, we still have to develop a parametric form for $\mathrm{E}\left(R_{i}\right)$ that takes into account the idiosyncratic risk premium. This will add two additional parameters and two additional moment restrictions.

\section{Modeling the idiosyncratic risk premium}

Theory does not necessarily predict a particular parametric relationship between idiosyncratic risk (as measured by dollar variance) and expected return. The model I developed above suggests the relationship should be piecewise linear, but there may be many pieces, and the pieces will generally have decreasing slopes. Graphs of idiosyncratic risk versus returns suggest that a well-fitting parametric model would be

$$
\mathrm{E}\left(R_{i}\right)=\lambda \sqrt{\sigma_{\$, i}^{2}}+R_{f}
$$

where $\lambda$ is a measure of the idiosyncratic risk premium and $R_{f}$ is the real interest rate. Figures 10, 14, and 17 plot these variables together.

This model immediately leads to the following two moment conditions. First, pricing errors must be zero in expectation:

$$
\mathrm{E}\left(R_{i}-\lambda \sigma_{\$, i}-R_{f}\right)=0
$$

Second, the pricing errors must be uncorrelated with the explanatory variable, so we aren't getting a well-fit model by just having it overestimate for low risk movies and underestimate for high risk movies:

$$
\mathrm{E}\left(\left(R_{i}-\lambda \sigma_{\$, i}-R_{f}\right) \sigma_{\$, i}\right)=0
$$

These two moment conditions are standard conditions for regressions. We now have $G+2$ parameters: $w_{g} s, \lambda$, and $R_{f}$, and we have $G+2$ moment conditions as well. The model is just-identified. I estimate the model using the Nelder-Mead 
simplex algorithm and confirm the algorithm output by testing whether the objective value equals zero at the parameter estimate.

\section{Econometric issues}

Standard GMM estimates have a few econometric issues:

- The explanatory variable $\sigma_{\$, i}^{2}$ is estimated, not observed precisely. So we will have the standard attenuation bias where the coefficient estimate for $\lambda$ will be biased towards zero. This is not a big deal, since if we corrected for it, it would go in our favor (make our estimate for $\lambda$ even higher than it already is).

- The error in estimating $\sigma_{\$, i}^{2}$ is correlated with the error in $R_{i}$. This is a smallsample bias resulting from the fact that the distribution of movie returns is heavily skewed. Specifically, a small group with high average returns may simply be a group that happened to get an extreme return from the right tail; in this case, it would seem like high variance of returns is correlated with high average returns, even when it is not.

- When data are heavy-tailed, asymptotic standard errors can be quite inaccurate for GMM estimates, especially in small samples. Also, the true (finitesample distribution) rejection regions may not be symmetric like the asymptotic distributions.

I use bootstrapping to address these issues. Following Horowitz (2001), bootstrap estimates benefit from "asymptotic refinements," or differences from the asymptotic distribution that make its approximation error to the true finite-sample distribution of smaller order in the number of data points.

Bootstrapping can also be useful for bias reduction. We can write bias as a function of the true population distribution:

$$
E(\hat{\lambda})=\lambda_{0}+b(F)
$$

where $\lambda_{0}$ is the true value of the parameter and $F$ is the population distribution. The bootstrap analog is to substitute $\hat{\lambda}$ for $\lambda_{0}$, and the empirical distribution $F_{N}$ for F:

$$
E^{*}(\hat{\lambda})=\hat{\lambda}+b\left(F_{N}\right)
$$


Thus, the expression $E^{*}(\hat{\lambda})-\hat{\lambda}$ will consistently estimate the bias $b(F)$ as $N \rightarrow \infty$. I find that the bias reductions are not too large, although the estimates are consistently reduced for every grouping characteristic.

\section{The interquartile range: a more robust estimator?}

When distributions are sufficiently heavy-tailed, we might be concerned that measures like variance simply become undefined. Even if the second moment is defined, our estimates of it might still be highly sensitive to tail events. A general approach to such problems is to use empirical quantiles of the data; for example, using the median instead of the mean, as we did in Figure 5. For measuring the spread of a distribution, we can use the interquartile range, or the difference between the 3rd and 1st quartiles of the distribution. Figures 8, 11, 15, and 18 plot expected returns against interquartile ranges for different groupings of movies (size, genre, director, and actor). The resulting patterns are consistent with the plots using dollar variance as the $x$-variable.

\section{Results}

Graphs of returns against risk and tables with GMM estimates can all be found at the end of the document. This section discusses these graphs and tables.

\section{Graphs}

- Figures 6, 9, 13, and 16: these figures plot expected returns against dollar variance for different projects. Each point represents a set of movies that share the same characteristic; for example, they might all be in the smallest $5 \%$ of movies by budget, or they might have the same genre. The first plot, figure 6, shows that budget size does not sort movies well for the purpose of creating spreads in expected returns; the other characteristics do.

- Figures 7, 10, 14, and 17: these figures are the same as the above, but put dollar volatility (standard deviation of dollar returns) instead of dollar variance on the $x$-axis. The results are fairly similar, and show that the relationship beween dollar volatility and expected return is approimately linear.

- Figures 8,11,15, and 18: these figures are the same as above, but put interquartile range of dollar returns on the $x$-axis. They show that even when 
we use a measure of risk that is more robust to heavy tails, the qualitative results still go through.

- Figure 12: this figure is the same as Figure 11, except with returns properly annualized (this applies only to a subset of the data for which I have production start and end dates).

\section{GMM Estimates}

Table 3 shows the main GMM results. The column $\hat{\lambda}$ shows the estimates of the idiosyncratic risk premium; for the three rows corresponding to grouping by genre, director, and actor, these range from 45 to 100 basis points per $\$ 1 \mathrm{MM}$ of dollar volatility. (I do not find statistically significant results when grouping by budget ventile, as shown in figure 6.) The $\hat{\lambda}_{b c}$ column shows bias-corrected estimates; these range from 44 to 119 basis points per million dollars of volatility.

The $95 \%$ confidence sets are generated using bootstrapping. The final three rows are statistically significant. The $R^{2}$ values are low because the differences in expected returns across films explains very little of the (extremely high) uncertainty about film returns.

To assess economic significance, I calculate the cross-sectional standard deviation of expected returns computed according to the model fit. I find that my estimates of the idiosyncratic risk premium $\lambda$ are large enough to induce sizeable variation in expected returns: for example, the fit using genre groupings implies a standard deviation in expected returns of 8.3 percentage points (compared to a median return of $17 \%$ in my dataset); and this is the lowest estimate.

In the rows corresponding to grouping movies by directors and actors, I use reduced samples. In the "Director" row, I keep only those films directed by directors with at least ten films; for the "Actor" row, I keep only those films that feature actors with at least thirty films. This helps mitigate the small-sample bias discussed above that might bias my results upward. Since these samples are smaller, they feature higher $R^{2}$ values, and the $\sigma\left(\hat{\mathrm{E}}\left(R_{i}\right)\right)$ values are also calculated with respect to these smaller samples.

Table 4 recalculates the results using geometric averaging in the specification for $\sigma_{\$, i}^{2}$ rather than artithmetic averaging. One might argue that geometric averaging is more appropriate in some cases; for example, we might imagine that having Brad Pitt in a movie reduces its risk to zero (hypothetically) since he is a big star. In that case, we would want a multiplicative factor representing Brad Pitt that just 
takes risk down to zero the moment he is in a film, even if there are other less-wellknown stars in the movie. In any case, the results are not too different using this alternative measure.

\section{Conclusions}

This paper has studied a cross-section of expected returns on real investments. In particular, I have focused on how film studios price risk. The evidence supports the idea that projects with higher levels of idiosyncratic risk will be developed only if they have higher expected returns. This finding contradicts the typical idea that diversifiable risk should not be priced.

Although the data do not clearly elucidate a mechanism for this phenomenon, we have seen a model in which agency frictions can explain this behavior. Specifically, there are deadweight costs imposed by financiers (perhaps monitoring costs, or expected bankruptcy costs) whenever firms take on risky investments. This causes the cost of capital to be higher for funding such investments, and makes corporate managers avoid them. 


\section{References}

[1] Alexa (2014). How popular is imdb.com? Web: http://www.alexa.com/siteinfo/imdb.com

[2] Ang A., R. Hodrick, Y. Xing, and X. Zhang. (2006). The cross-section of volatility and expected returns. Journal of Finance, 61(1).

[3] Belo, F. (2010) Production-based measures of risk for asset pricing. Journal of Monetary Economics, 57, 146-163.

[4] Bollerslev, T. (1986). Generalized autoregressive conditional heteroskedasticity. Journal of Econometrics, 31(3), 307-327.

[5] Campbell, J. and L. Hentschel (1992). No news is good news: an asymmetric model of changing volatility in stock returns. Journal of Financial Economics 31, 281-318.

[6] Elberse, A. (2013). Blockbusters: Hit-making, risk-taking, and the big business of entertainment. Macmillan.

[7] Engle, R. (1982). Autoregressive conditional heteroscedasticity with estimates of the variance of United Kingdom inflation. Econometrica, 987-1007.

[8] Fazzari, S., R. G. Hubbard, and B. Petersen (1988). Financing constraints and corporate investment. Brookings Papers on Economic Activity 1988, 141-195.

[9] Ferrari, M. and A. Rudd (2008). Investing in movies. Journal of Asset Management, 9(1).

[10] Freedman, D. (1981). Boostrapping regression models. Annals of Statistics, 9(6).

[11] Froot, K., D. Scharfstein, and J. Stein (1993). Risk management: coordinating corporate investment and financing policies. Journal of Finance, 48(5).

[12] Greenwood, R. and S. Hanson (2013). Waves in ship prices and investment. Working paper, National Bureau of Economic Research, No. 19246.

[13] Hall P. and J. Horowitz (1996). Bootstrap critical values for tests based on generalized-method-of-moments estimators. Econometrica, 64(4). 
[14] Hickey, W. (2014). The dollar-and-cents case against Hollywood's exclusion of women. http://fivethirtyeight.com/features/the-dollar-and-centscase-against-hollywoods-exclusion-of-women/

[15] Hirshleifer, D. and A. Thakor (1992). Managerial conservatism, project choice, and debt. Review of Financial Studies, 5(3), 437-470.

[16] Holmstrom, B. (1989). Agency costs and innovation. Journal of Economic Behavior and Organization, 12, 305-327.

[17] Horowitz, J. (2001). The bootstrap. Handbook of Econometrics, 5, 3159-3228. J. Heckman and E. Leamer, eds.

[18] IMDB (2014). How to add yourself to IMDb. Web: http://www.imdb.com/help/show_leaf?resumeaddnewname

[19] Kashyap, A., T. Hoshi, and D. Scharfstein (1991). Corporate structure, liquidity and investment: evidence from Japanese industrial groups. Quarterly Journal of Economics, 106, 33-60.

[20] Lintner, J. (1965). The valuation of risk assets and the selection of risky investments in stock portfolios and capital budgets. The Review of Economics and Statistics, 13-37.

[21] Merton, R. (1987). A simple model of capital market equilibrium with incomplete information. Journal of Finance, 42(3).

[22] Mossin, J. (1966). Equilibrium in a capital asset market. Econometrica, 768-783.

[23] Nardone, J. (1982). Is the movie industry countercyclical? Cycles.

[24] Rauh, J. (2006). Investment and financing constraints: evidence from the funding of corporate pension plans. Journal of Finance, 61, 33-71.

[25] Ravid, S. A. (1999). Information, blockbusters, and stars: a study of the film industry. Journal of Business, 72(4).

[26] Sharpe, W. (1964). Capital asset prices: a theory of market equilibrium under conditions of risk. Journal of Finance, 19(3), 425-442.

[27] Smith, and R. Stulz (1985). The determinants of firms' hedging policies. Journal of Financial and Quantitative Analysis, 20(4), 391-405. 
[28] Stein, Jeremy C. (2003), Agency, information and corporate investment. Handbook of the Economics of Finance, Chapter 2. Edited by George Constantinides, Milton Harris and Rene Stulz. Amsterdam: North-Holland.

[29] Treynor, J. (1961). Toward a theory of market value of risky assets. Unpublished manuscript.

[30] Vogel, H. (2011). Entertainment industry economics: a guide for financial analysis. New York: Cambridge University Press.

[31] Weinraub, B. (1995). 'Gump,' a huge hit, still isn't raking in huge profits? Hmm. The New York Times, http://www.nytimes.com/1995/05/25/movies/gump-a-huge-hit-stillisn-t-raking-in-huge-profits-hmm.html 


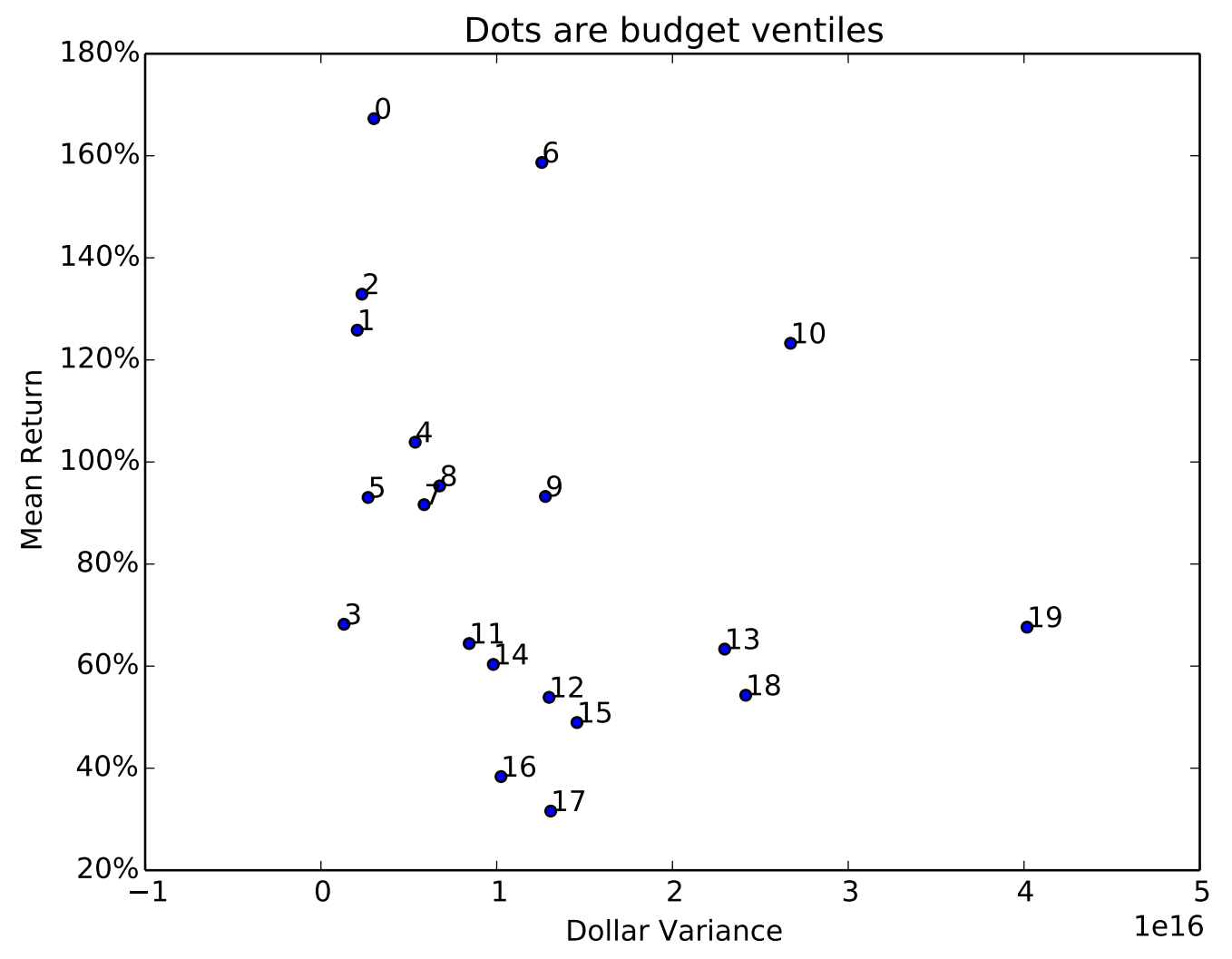

Figure 6: No clear relationship when movies are bucketed by budget ventile $(0=$ smallest ventile) 


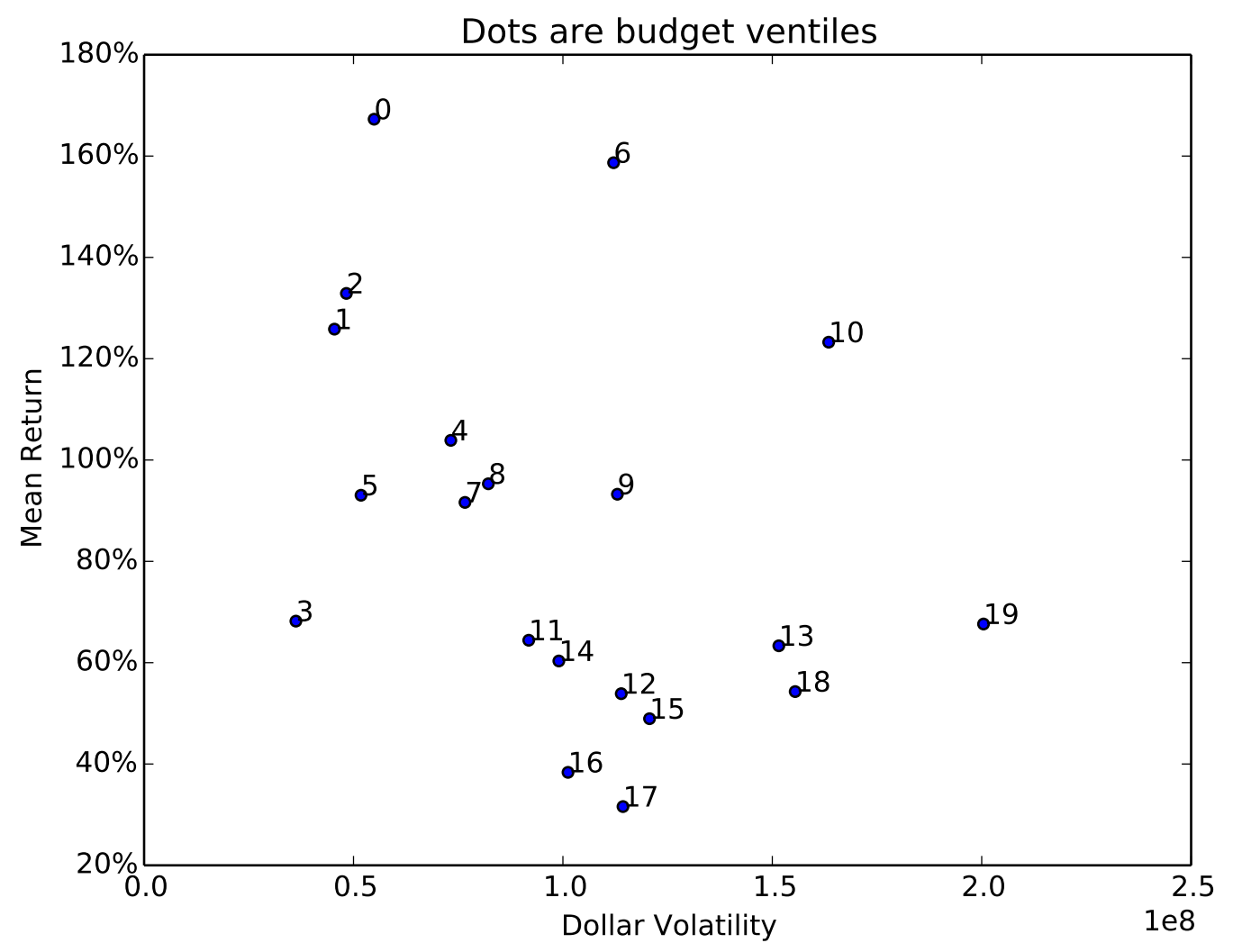

Figure 7: Budget Ventiles, dollar volatility on the $x$-axis $(0=$ smallest ventile $)$ 


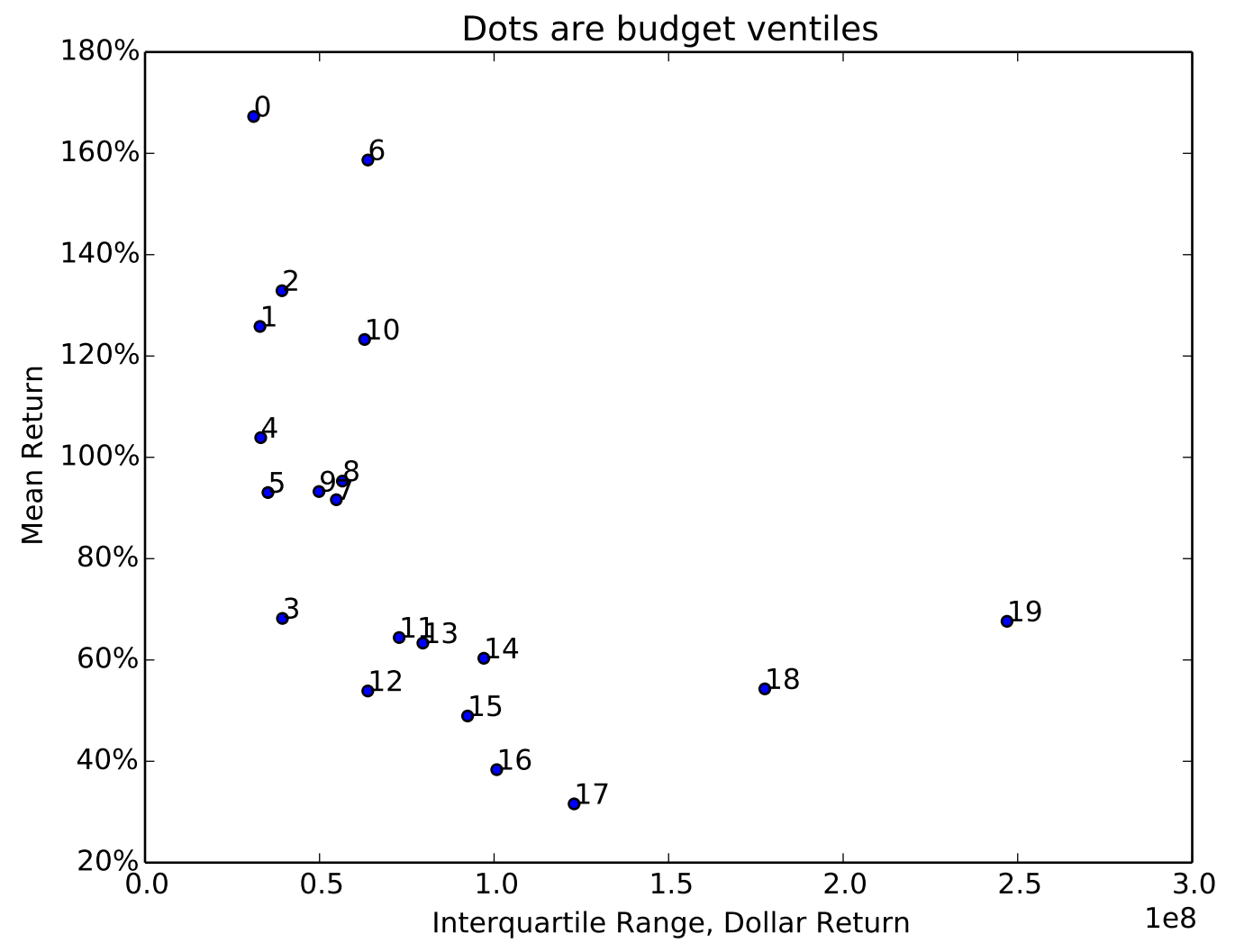

Figure 8: Budget Ventiles, interquartile range on the $x$-axis $(0=$ smallest ventile $)$ 


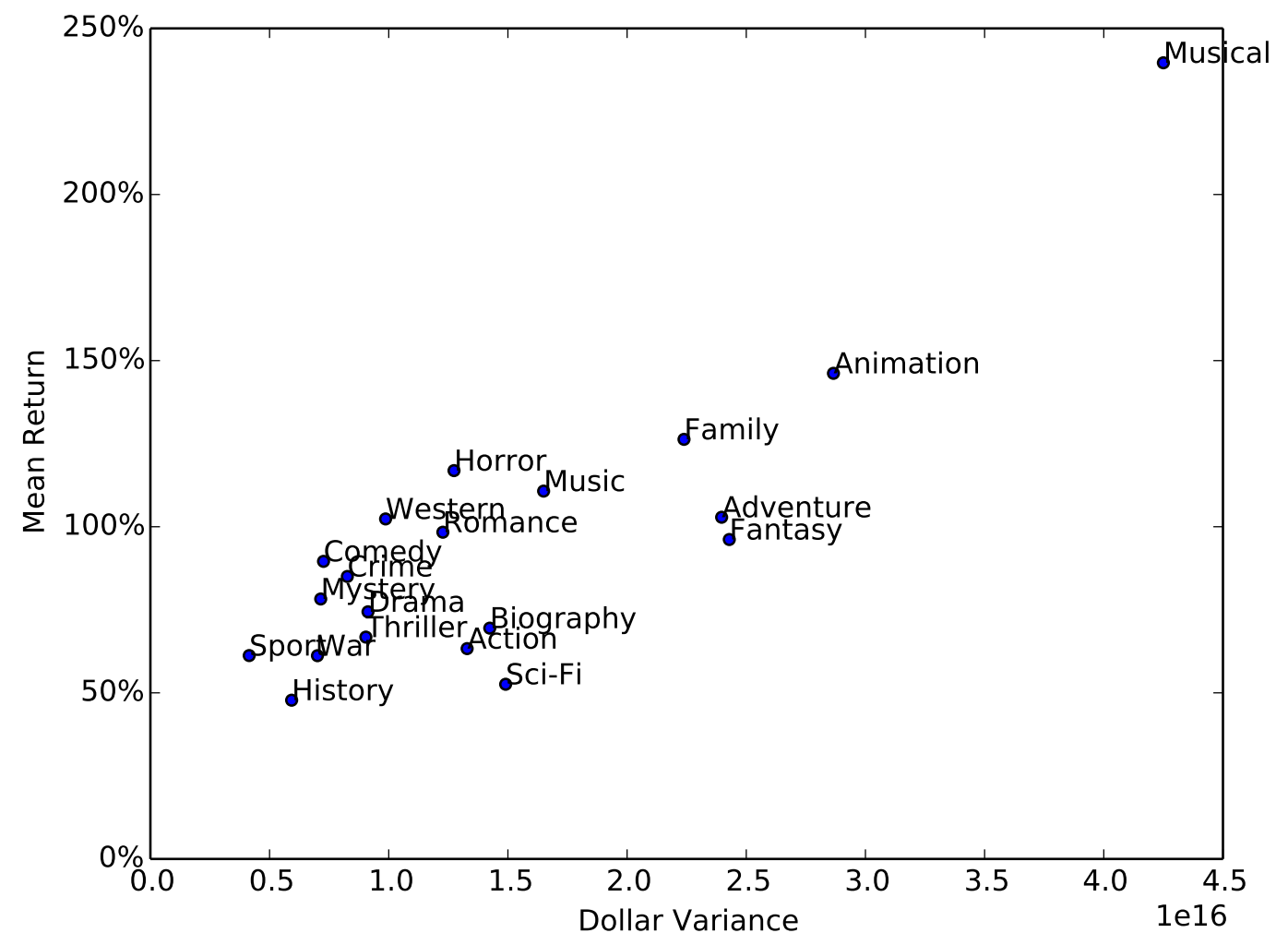

Figure 9: Idiosyncratic risk premium, grouping movies by genre 


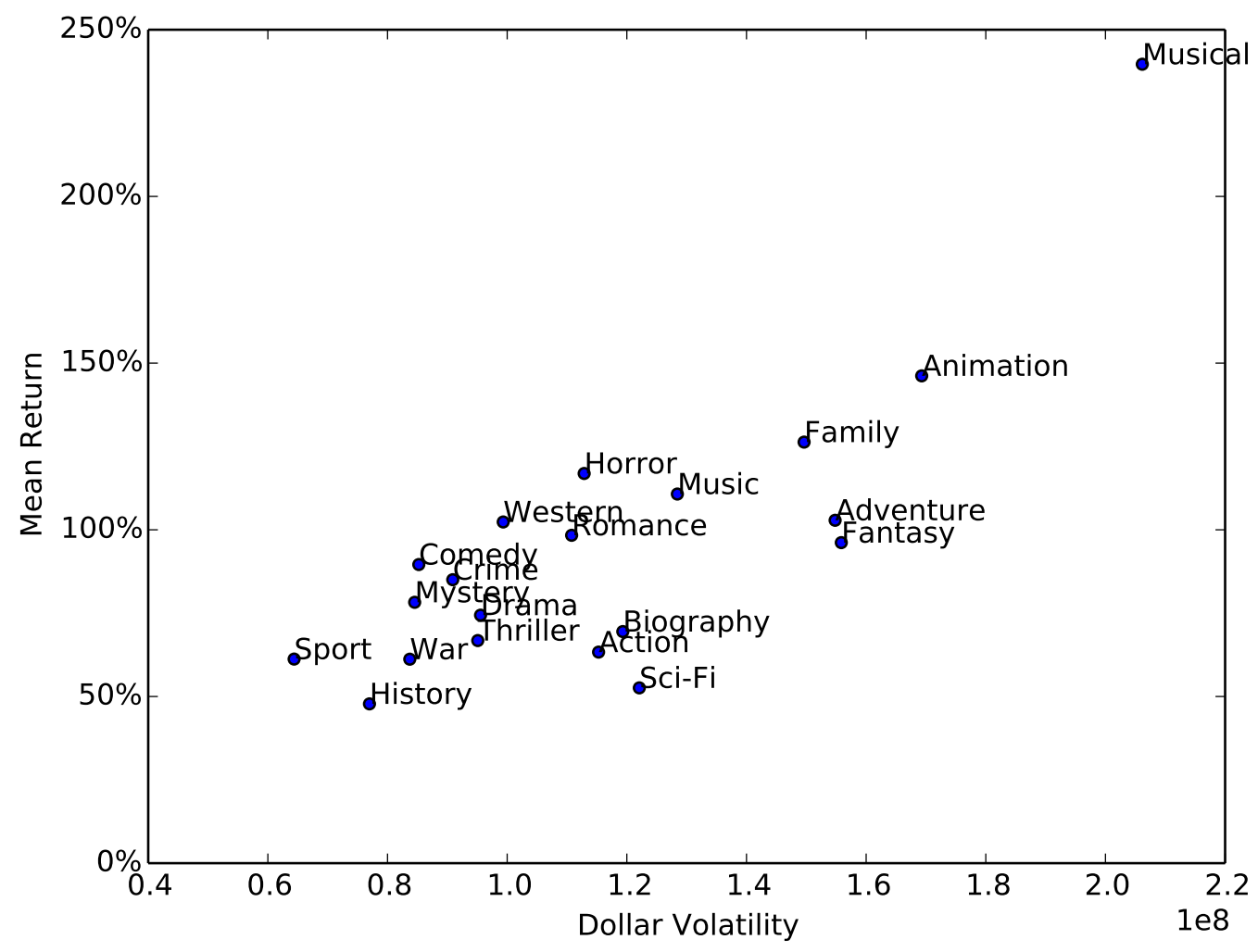

Figure 10: Idiosyncratic risk premium, grouping movies by genre, dollar volatility on the $x$-axis 


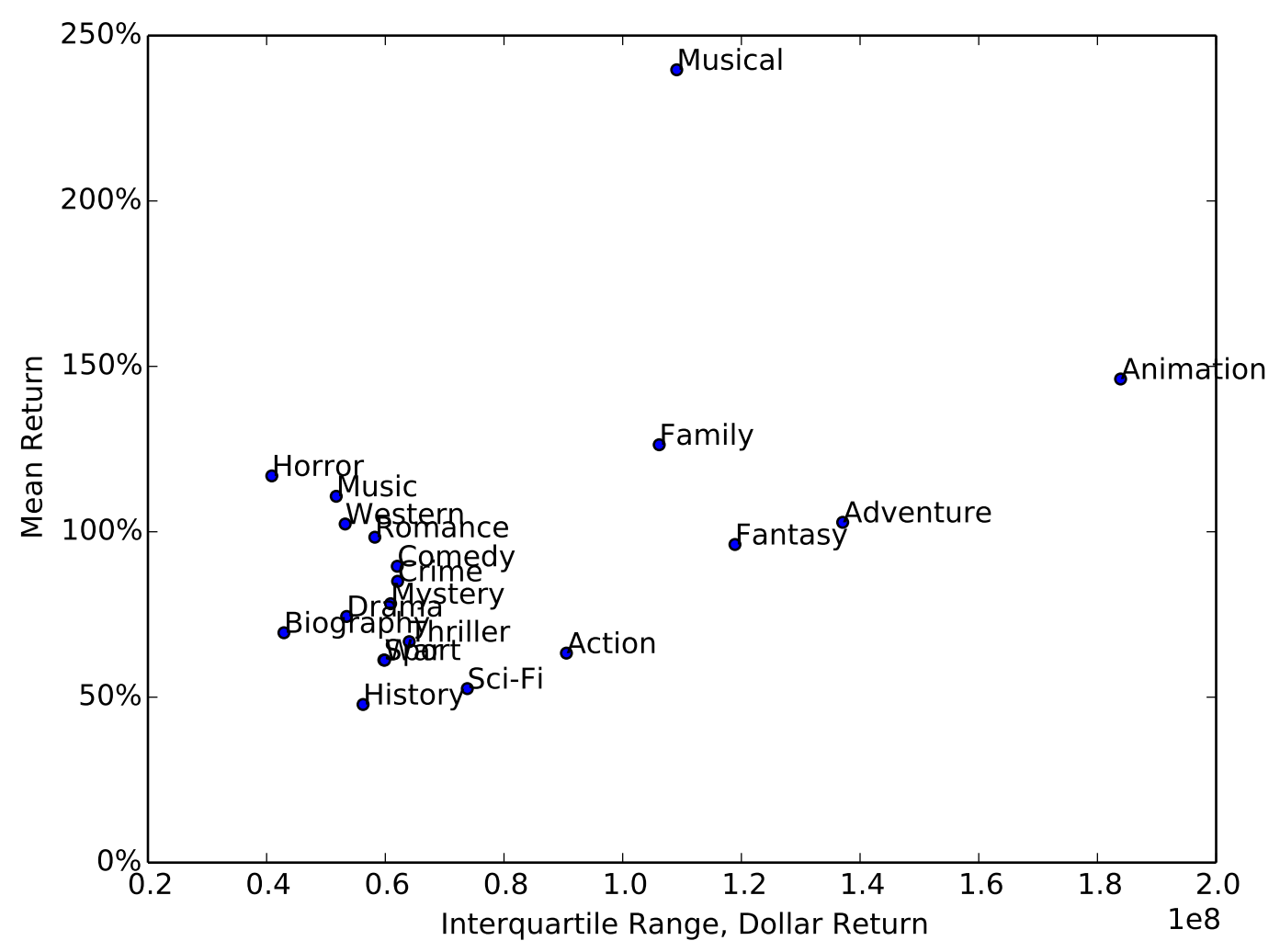

Figure 11: Idiosyncratic risk premium, grouping movies by genre, interquartile range on the $x$-axis 


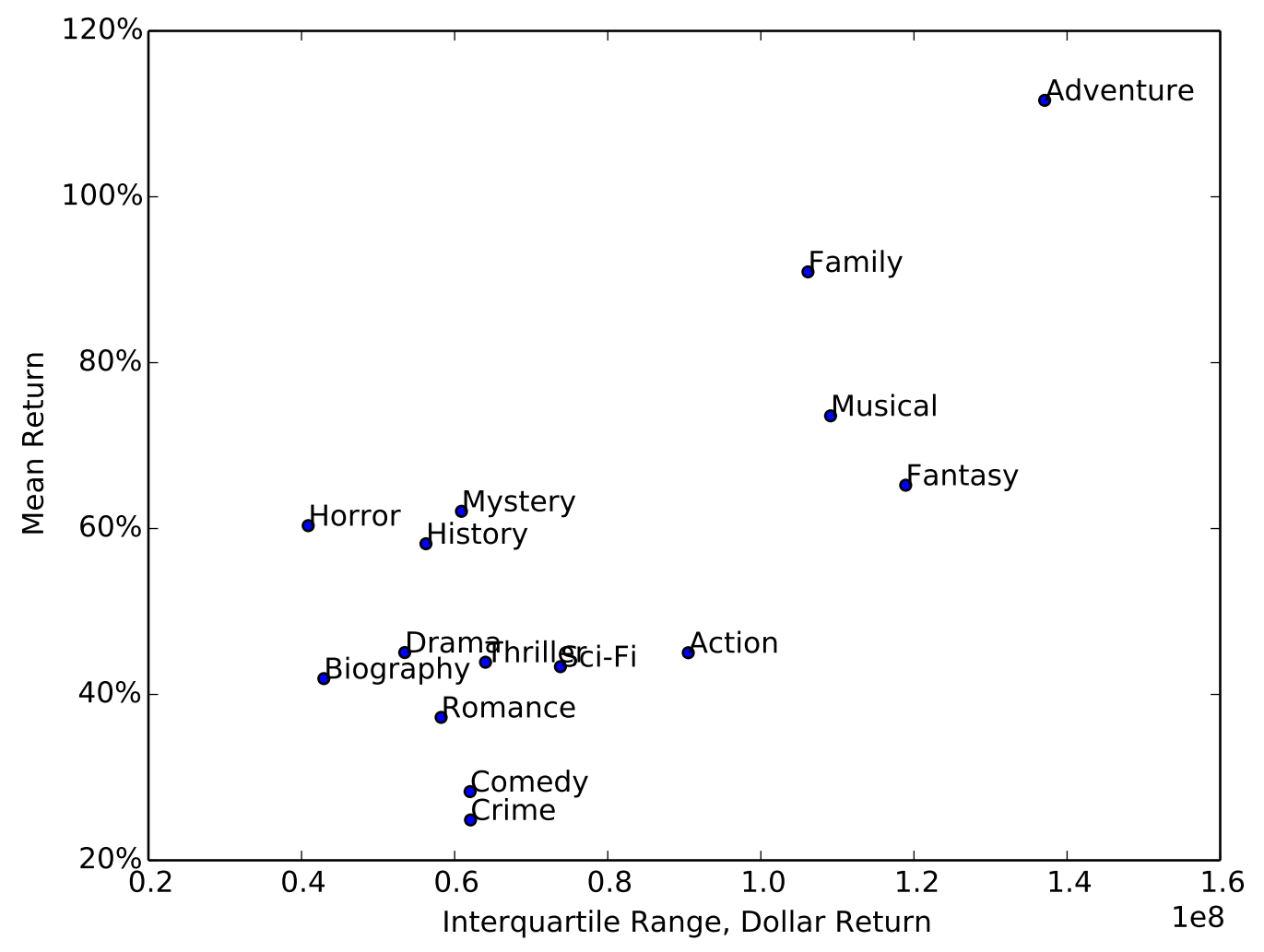

Figure 12: Idiosyncratic risk premium, grouping movies by genre, interquartile range on the $x$-axis. The returns are annualized using IMDB data and winsorized at $300 \%$. Some genres do not appear since they have fewer than ten movies; the cutoff used in Figures 9, 10, and 11 is thirty movies. 


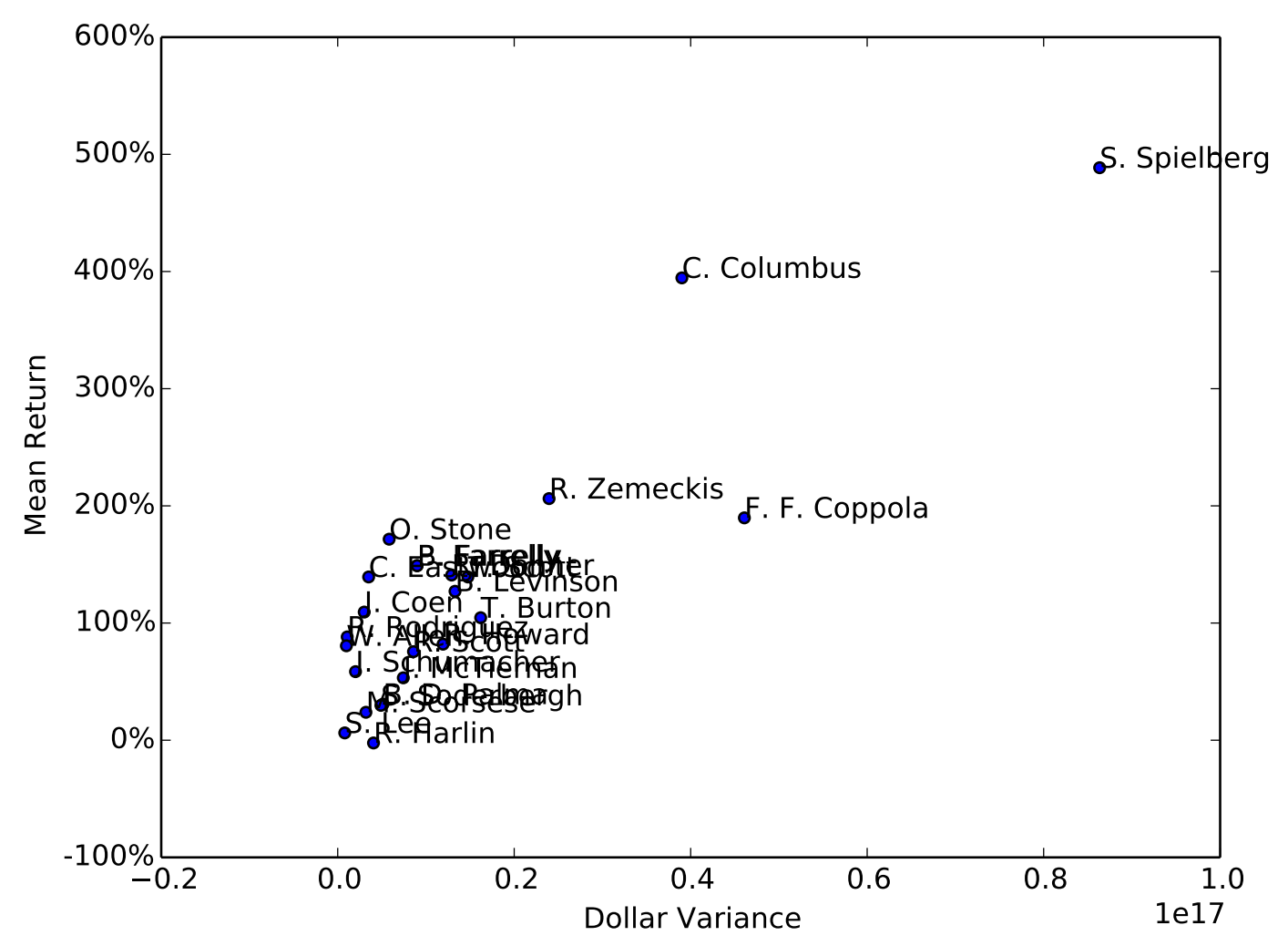

Figure 13: Idiosyncratic risk premium, grouping movies by director 


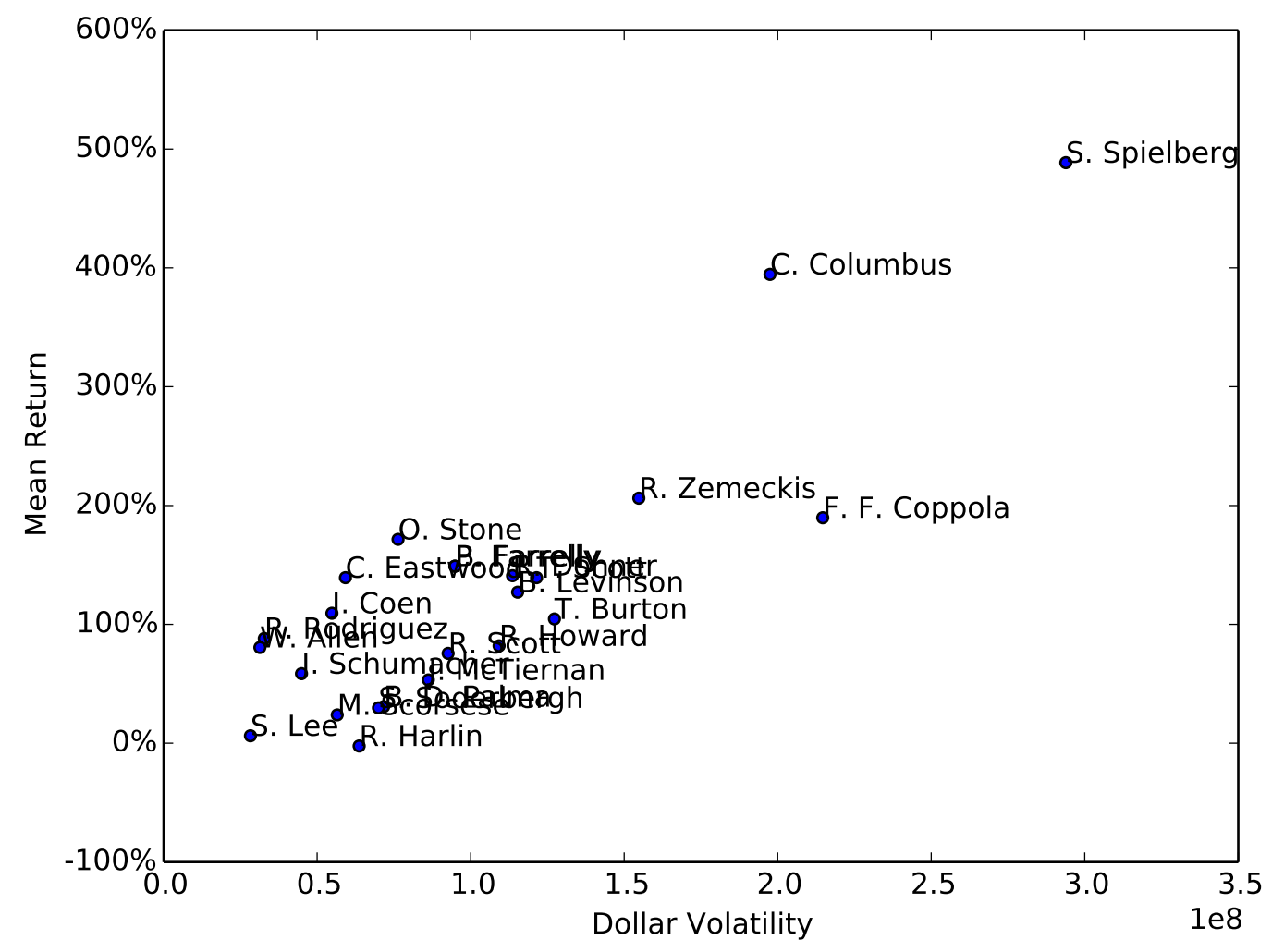

Figure 14: Idiosyncratic risk premium, grouping movies by director, dollar volatility on the $x$-axis 


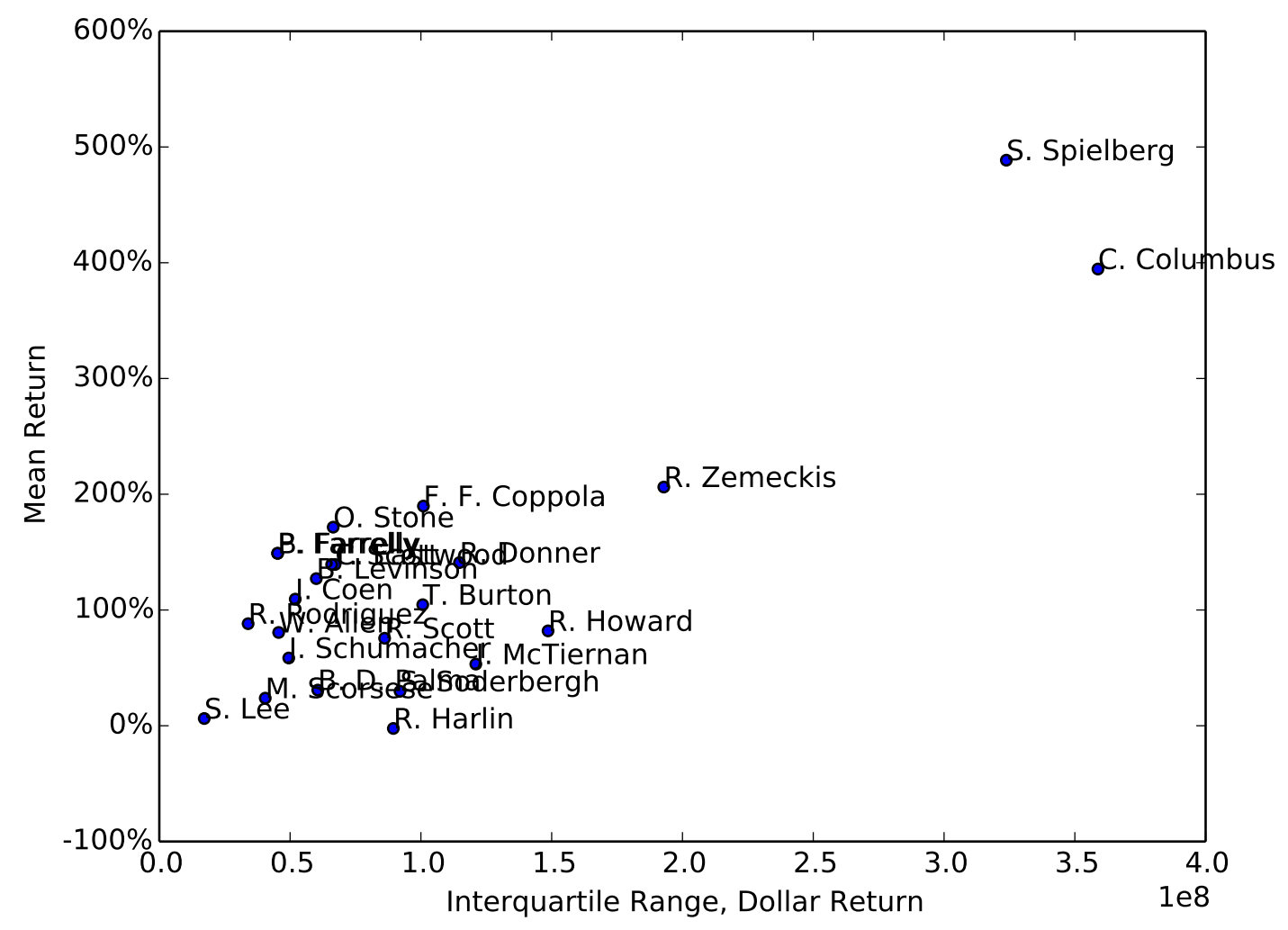

Figure 15: Idiosyncratic risk premium, grouping movies by director, interquartile range on the $x$-axis 


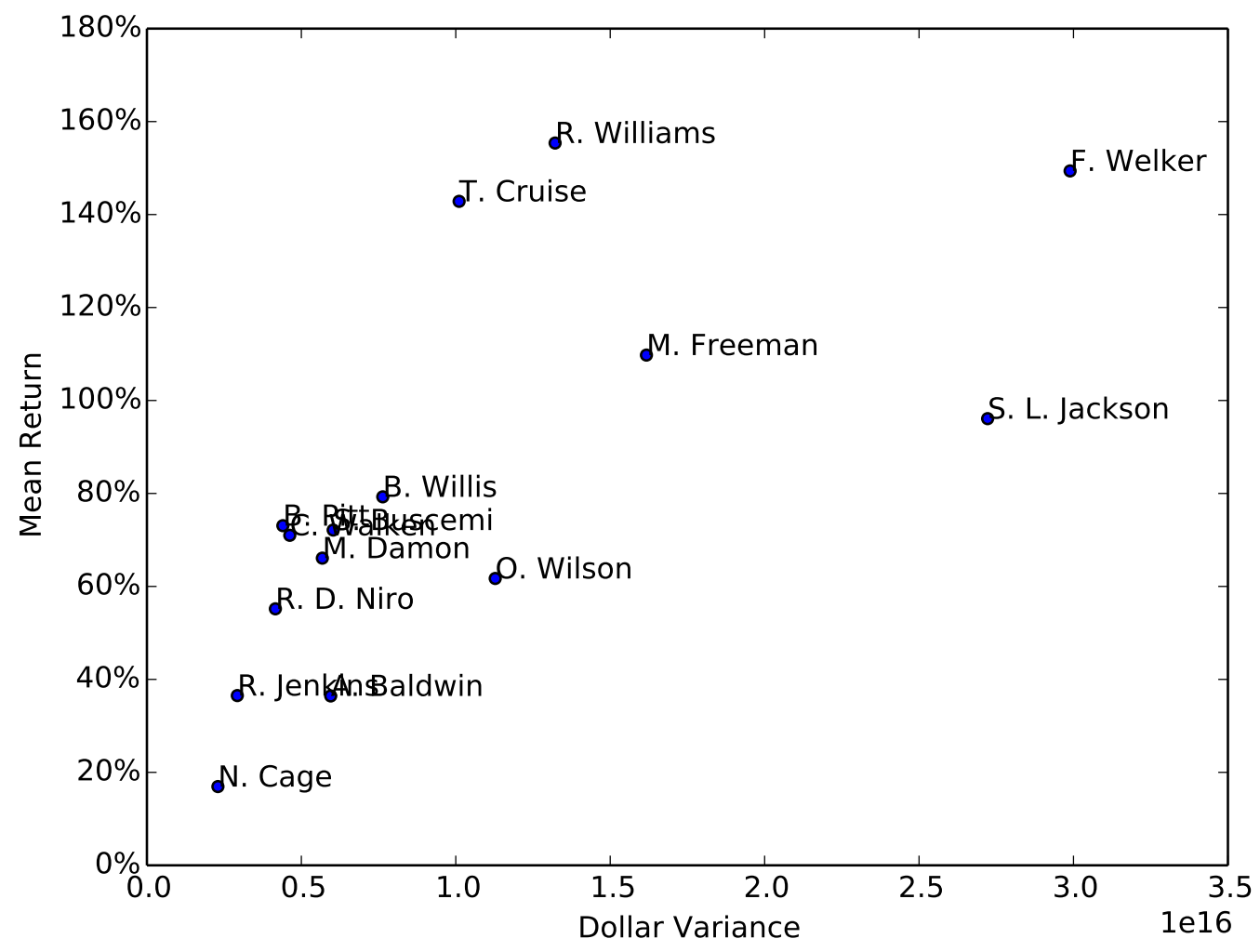

Figure 16: Idiosyncratic risk premium, grouping movies by actor 


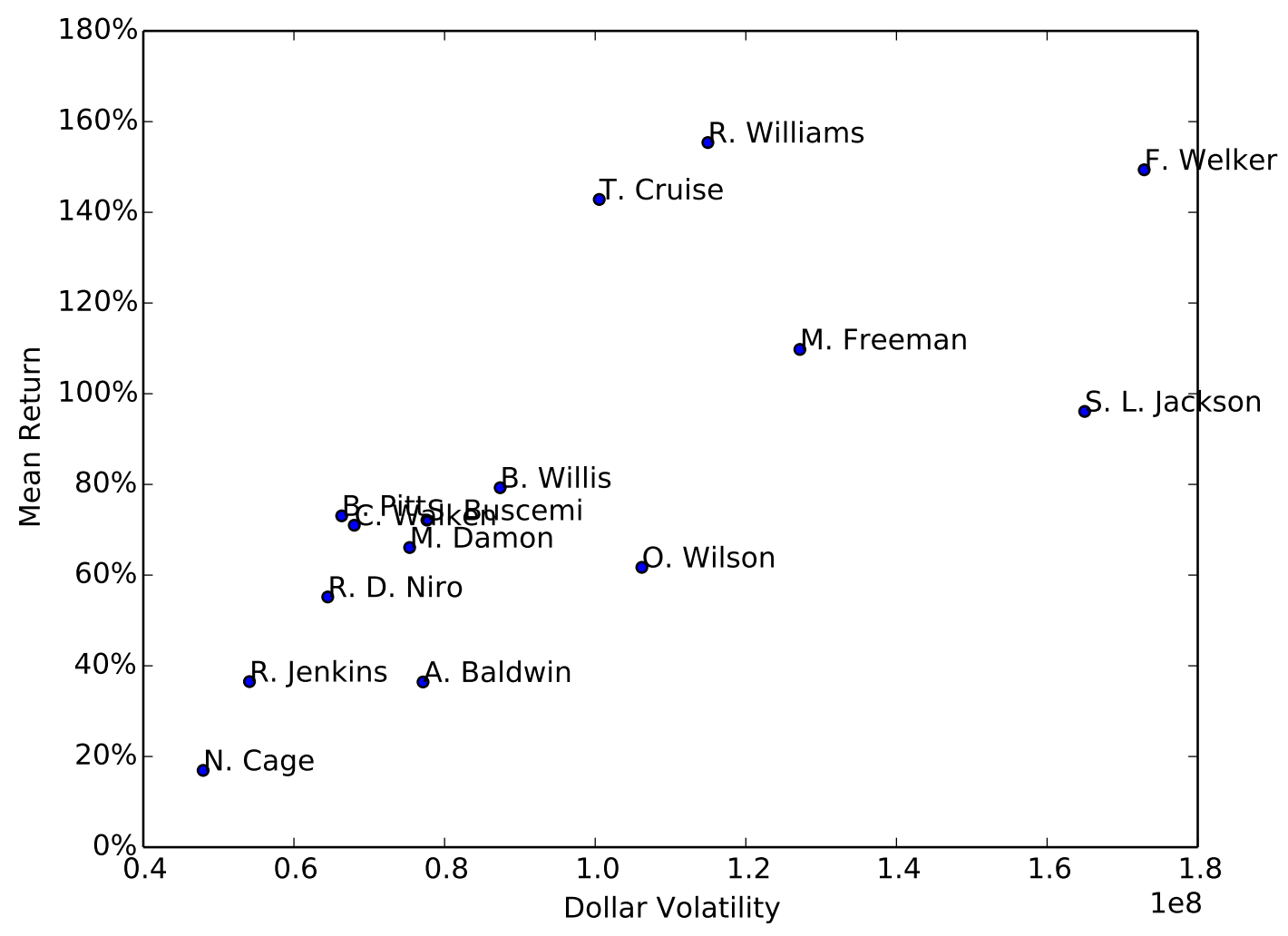

Figure 17: Idiosyncratic risk premium, grouping movies by actor, dollar volatility on $x$-axis 


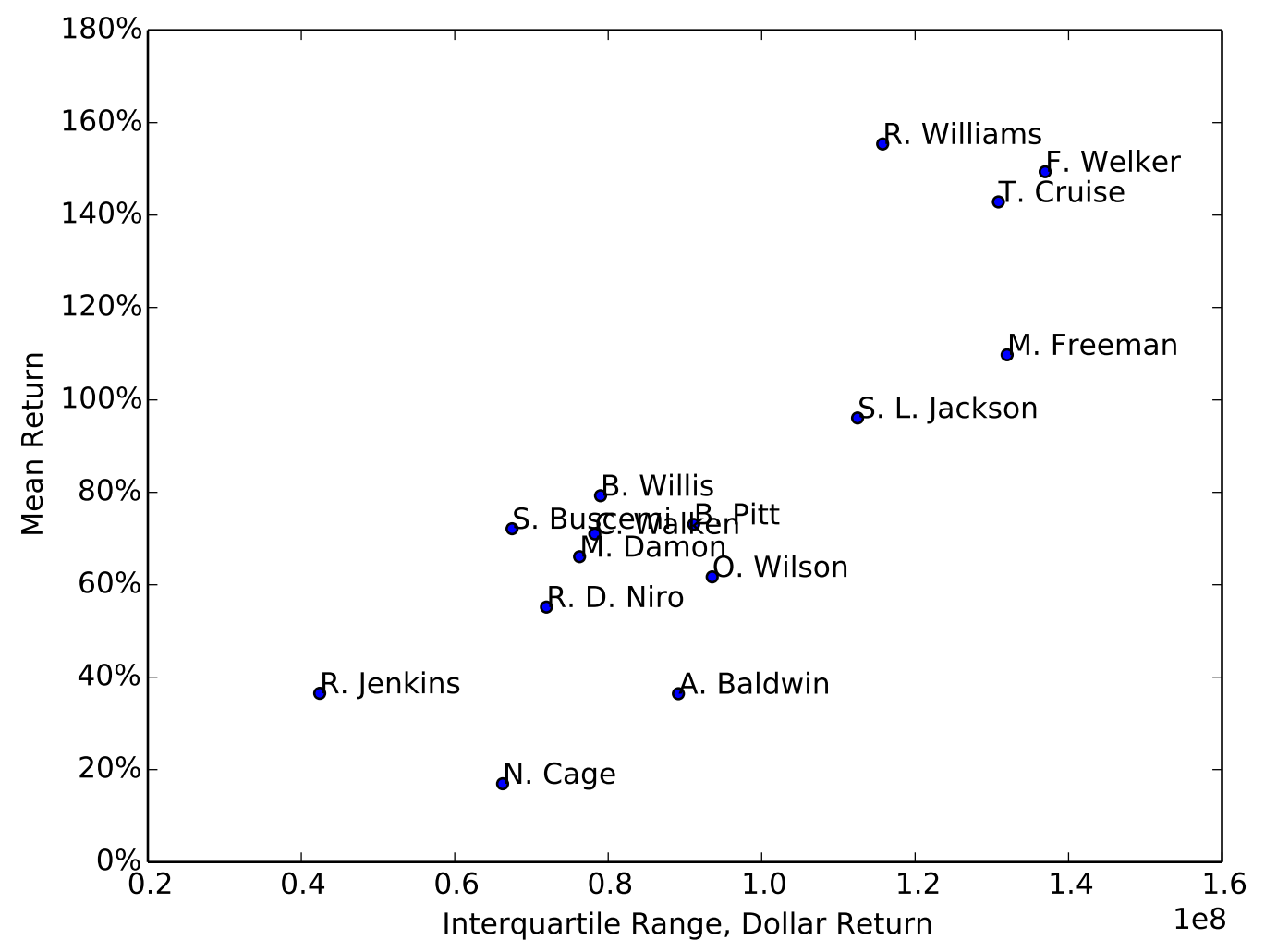

Figure 18: Idiosyncratic risk premium, grouping movies by actor, interquartile range on $x$-axis 


$$
\begin{gathered}
\mathrm{E}\left(R_{i}\right)=\lambda \sqrt{\sigma_{\$, i}^{2}}+R_{f} \\
\sigma_{\$, i}^{2}=\sum_{g} w_{g} 1_{i g} / \sum_{g} 1_{i g} \\
\text { Estimated: }\left\{w_{g}\right\}, \lambda, R_{f}
\end{gathered}
$$

\begin{tabular}{|c|c|c|c|c|c|c|}
\hline \multirow[b]{2}{*}{ Grouping Characteristic } & \multirow[b]{2}{*}{$\hat{\lambda}$} & \multirow[b]{2}{*}{$\hat{\lambda}_{b c}$} & \multicolumn{4}{|l|}{ Bootstrap 95\% } \\
\hline & & & Confidence Set & $R^{2}$ with $\hat{\lambda}_{b c}$ & $\widehat{R}_{f}$ & $\sigma\left(\hat{\mathrm{E}}\left(R_{i}\right)\right)$ \\
\hline Budget Ventile & -34 bps /MM\$ & $-50 \mathrm{bps} / \mathrm{MM} \$$ & {$[-49,17] \mathrm{bps} / \mathrm{MM} \$$} & $0.0 \%$ & $121 \%$ & $14.5 \%$ \\
\hline Genre & 45 & 44 & {$[39,52]$} & $0.3 \%$ & $45 \%$ & $8.3 \%$ \\
\hline Director $(\geq 10 \text { films })^{1}$ & 117 & 116 & {$[73,151]$} & $10.2 \%$ & $10 \%$ & $118 \%$ \\
\hline Actor $\left(\geq 30\right.$ films $^{1}$ & 100 & 119 & {$[41,135]$} & $3.3 \%$ & $-15 \%$ & $35.3 \%$ \\
\hline
\end{tabular}

Boldface denotes statistical significance.

$\sigma_{\$, i}^{2}$ is the dollar variance of returns, measured in $(\mathrm{MM} \$)^{2} . E\left(R_{i}\right)$ is measured in percentage points.

$\hat{\lambda}_{\mathrm{bc}}$ is $\hat{\lambda}$ estimated by GMM, corrected for bias with a bootstrap estimate of the bias. $\lambda$ is measured in \% per MM \$ of dollar vol. $R^{2} \equiv 1-R S S / T S S$, where $R S S \equiv \sum_{i}\left(R_{i}-\hat{\lambda}_{b c} \sqrt{\hat{\sigma}_{\$, i}^{2}}-\hat{R}_{f}\right)^{2}$ and TSS $\equiv \sum_{i}\left(R_{i}-\bar{R}\right)^{2}$

${ }^{1}$ To reduce small-sample bias, I use only actors with at least 30 films and directors with at least 10 films. The $R^{2}$ and $\sigma\left(\hat{\mathrm{E}}\left(R_{i}\right)\right)$ reflect this smaller sample for directors and actors.

Table 3: GMM estimates of the price of idiosyncratic risk, with arithmetic averaging for $\sigma_{\Phi, i}^{2}$. 


$$
\begin{gathered}
\mathrm{E}\left(R_{i}\right)=\lambda \sqrt{\sigma_{\$, i}^{2}}+R_{f} \\
\sigma_{\$, i}^{2}=\exp \left(\sum_{g} \ln \left(w_{g}\right) 1_{i g} / \sum_{g} 1_{i g}\right) \\
\text { Estimated: }\left\{w_{g}\right\}, \lambda, R_{f}
\end{gathered}
$$

\begin{tabular}{|c|c|c|c|c|c|c|}
\hline \multirow[b]{2}{*}{ Grouping Characteristic } & \multirow[b]{2}{*}{$\hat{\lambda}$} & \multirow[b]{2}{*}{$\hat{\lambda}_{b c}$} & \multicolumn{4}{|l|}{ Bootstrap 95\% } \\
\hline & & & Confidence Set & $R^{2}$ with $\hat{\lambda}_{b c}$ & $\widehat{R}_{f}$ & $\sigma\left(\hat{\mathrm{E}}\left(R_{i}\right)\right)$ \\
\hline Budget Ventile & -34 bps /MM\$ & $-50 \mathrm{bps} / \mathrm{MM} \$$ & {$[-49,17] \mathrm{bps} / \mathrm{MM} \$$} & $0.0 \%$ & $121 \%$ & $14.5 \%$ \\
\hline Genre & 47 & 43 & {$[17,89]$} & $0.7 \%$ & $43 \%$ & $22.3 \%$ \\
\hline Director ( $\geq 10$ films) & 117 & 116 & {$[73,151]$} & $10.2 \%$ & $10 \%$ & $118 \%$ \\
\hline Actor ( $\geq 30$ films) & 82 & 91 & {$[39,119]$} & $2.6 \%$ & $-3 \%$ & $31.1 \%$ \\
\hline
\end{tabular}

Boldface denotes statistical significance.

$\sigma_{\$, i}^{2}$ is the dollar variance of returns, measured in $(\mathrm{MM} \$)^{2} . E\left(R_{i}\right)$ is measured in percentage points.

$\hat{\lambda}_{\mathrm{bc}}$ is $\hat{\lambda}$ estimated by GMM, corrected for bias with a bootstrap estimate of the bias. $\lambda$ is measured in \% per MM \$ of dollar vol. $R^{2} \equiv 1-R S S / T S S$, where $R S S \equiv \sum_{i}\left(R_{i}-\hat{\lambda}_{b c} \sqrt{\hat{\sigma}_{\$, i}^{2}}-\hat{R}_{f}\right)^{2}$ and TSS $\equiv \sum_{i}\left(R_{i}-\bar{R}\right)^{2}$.

To reduce small-sample bias, I use only actors with at least 30 films and directors with at least 10 films. The $R^{2}$ and $\sigma\left(\hat{\mathrm{E}}\left(R_{i}\right)\right)$ reflect this smaller sample for directors and actors.

Table 4: GMM estimates of the price of idiosyncratic risk, with geometric averaging for $\sigma_{\Phi, i}^{2}$. 